\title{
Considerações sobre a Pré e a Proto-história da serra do Montemuro e seu aro (centro-norte de Portugal): artefactos metálicos e seu contexto
}

\section{Some reflections on the Late Prehistory of the Montemuro region and its surroundings (central-northern Portugal): Metal artefacts and their context}

Domingos J. Cruz (*)

Diana Fernandes (**)

Xosé-Lois Armada ( ${ }^{* * *}$ )

Raquel Vilaça $\left.{ }^{* * * *}\right)$

Recibido: 23-03-2018

Aceptado: 19-09-2018

\begin{abstract}
Resumo
Neste artigo oferecemos uma revisão exaustiva da metalurgia do Calcolítico e Idade do Bronze da serra do Montemuro e áreas geográficas imediatas, identificáveis com o interflúvio Douro/Paiva e os planaltos centrais. O repertório de materiais conhecidos ascende a 13 objectos, que estudamos prestando especial atenção aos seus problemas de identificação, contextualização e composição química. Apresentamos novas análises de um machado de alvado e fazemos a revisão da informação analítica disponível para outros três artefactos. Os diferentes metais e ligas empregadas explicam-se, em parte, pelas diferenças cronológicas entre as peças, mas também por razões de carácter cultural. $\mathrm{Na}$ área de estudo documentam-se machados de alvado em ligas binárias e ternárias, tratando-se de uma zona transicional ou de fronteira entre as situadas a norte (machados de alvado com ligas ternárias) e a sul (ligas binárias). Os achados de dois moldes metálicos, um deles na área limítrofe, apontam também para a produção local de diferentes tipos de machados no Bronze Final. Visando uma futura contextualização crono-cultural das comunidades, procede-se à tentativa de integração e comparação dos elementos arqueológicos, procurando o seu enquadramento na Pré e Proto-história regional.
\end{abstract}

Palavras-chave: machados de bronze; arqueometalurgia; Calcolítico; Idade do Bronze; serra do Montemuro; Beira Alta (Portugal).

(*) Faculdade de Letras da Universidade de Coimbra Departamento de História, Estudos Europeus, Arqueologia e Artes. Instituto de Arqueologia. Centro de Estudos Pré-históricos da Beira Alta - CEPBA. domingos.cruz@fl.uc.pt

(**) Mestre em Arqueologia e Território, Faculdade de Letras da Universidade de Coimbra. dianaefernandes@gmail.com https://orcid.org/0000-0003-1000-3654

(***) Instituto de Ciencias del Patrimonio (Incipit), Consejo Superior de Investigaciones Científicas (CSIC). xose- lois.armada@incipit.csic.es https://orcid.org/00000002-0110-0201

$(* * * *)$ Faculdade de Letras da Universidade de Coimbra. Departamento de História, Estudos Europeus, Arqueologia e Artes. Instituto de Arqueologia. Centro de Estudos Pré-históricos da Beira Alta - CEPBA; Centro de Estudos em Arqueologia, Artes e Ciências do Património - CEAACP. rvilaca@fl.uc.pt https://orcid.org/0000-0003-0019-7256 


\begin{abstract}
This article provides a thorough review of the Chalcolithic and Bronze Age metallurgy from the Montemuro range and its adjacent area, located between the Rivers Douro and Paiva and on the central high plateau. The known repertoire is made up of 13 artefacts, which are studied here paying particular attention to the problems of their identification, contextualization and chemical composition. We present new analyses of a socketed axe and we review the analytical results available for another three objects. The several metals and alloys can be explained, to some extent, by the chronological differences between the artefacts, as well as to cultural factors. Socketed axes with both binary and ternary alloys are detected in the study area, which is considered a transitional or border zone between those located to the north (socketed axes with leaded alloys) and those to the south (socketed axes with binary alloys). The finds of two metallic moulds, one of them in the adjacent area, points to the local production of several types of axes during the Late Bronze Age. Aiming at a future chrono-cultural contextualization of these communities, we attempt to integrate the archaeological information into a wider framework, that of the regional late prehistory.
\end{abstract}

Key words: bronze axes; archaeometallurgy; Chalcolithic; Bronze Age; serra do Montemuro; Beira Alta (Portugal).

\section{INTRODUÇÃO}

Tendo tido como propósito inicial o estudo e análise da composição química de um machado de alvado e duplo anel proveniente "Das abas do Montemuro", este trabalho desenvolve essa vertente, completando-a com outros testemunhos materiais. Compilaram-se os vários machados metálicos atribuídos, não só à serra do Montemuro, mas, mais genericamente, aos planaltos da Nave ("serra da Nave") e sub-região do Alto Paiva $^{2}$.

Centramo-nos, por ora, nessas peças, identificando-as e caracterizando-as genericamente, com base na respectiva informação disponível, nomeadamente de cariz bibliográfico, que foi analisada de forma bastante exaustiva. Tipos, tecnologias e contextos, quando conhecidos, permitem inseri-las no Calcolítico e Idade do Bronze, alcançando os primeiros momentos da Idade do Ferro.

Este texto pretende tecer algumas reflexões de conjunto sobre essas evidências, aprofundando os contextos de achado e articulação com o território, o que é feito pela primeira vez. Constitui, assim, uma síntese de aproximação ao conhecimento do povoamento pré e proto-histórico da região com base nas materialidades metálicas e sua integração no contexto do extremo ocidental da Península Ibérica. Em trabalhos futuros atender-se-á a uma caracterização pormenorizada dos arte-

1 Poster apresentado às VI Jornadas de Arqueologia do Vale do Douro (Porto, Novembro de 2016): X.-L. Armada, D. Fernandes, D. Cruz, R. Vilaça, "Machado do Bronze Final da serra do Montemuro (centro-norte de Portugal): o contributo da arqueometria". Agradece-se ao Director do Museu Nacional de Arqueologia, Dr. António Carvalho, a autorização concedida para procedermos ao estudo do machado.

2

Incluímos também neste trabalho uma lâmina serrilhada com lingueta de encabamento, pertencente às colecções do factos metálicos, ampliando o número de peças analisadas e aplicando outras técnicas de análise complementares.

\section{ENQUADRAMENTO GEOGRÁFICO}

A Beira Alta, do ponto de vista geomorfológico, corresponde a extensa superfície de aplanamento que se desenvolve a norte da Cordilheira Central. A serra do Caramulo, o designado "Maciço da Gralheira" (Girão, 1921: 63; Ribeiro et al., 1943; Ferreira, 1978)³ e a serra do Montemuro constituem os seus limites mais ocidentais (Fig. 1). A leste, os afluentes do Douro, correndo paralelamente, segundo a direcção S$\mathrm{N}$, por vezes ocupando vales de fractura, profundos e entalhados, como o Távora, o Torto e a ribeira de Teja, já nos limites do prolongamento para oeste da "superfície da Meseta" (Ferreira, 1978). O Douro e o Mondego limitam-na a norte e a sul.

O maciço do Montemuro, um "conjunto de formas doces" acima dos 1000 metros, como se lhe refere O. Ribeiro (1948: 334), integra as "montanhas ocidentais", que separam a plataforma litoral dos planaltos da Beira Alta, constituindo importante barreira natural às influências atlânticas, pois actuam como "centros de condensação e retenção da humidade oceânica" (Ribeiro, 1994: 742), com consequências importantes ao nível climático e do coberto vegetal. É uma unida-

Museu Nacional de Arqueologia, bem como o conhecido molde de fundição de machados de talão de duplo anel de Vila Boa (Castro Daire), que integra o acervo do Museu de História Natural da Faculdade de Ciências da Universidade do Porto. Ambas as peças foram recolhidas na serra do Montemuro, ou seu aro.

3 Integrando os diferentes relevos que se intercalam entre a serra do Montemuro e a serra do Caramulo (S. Macário, Arada, Gralheira, Freita, etc.). 


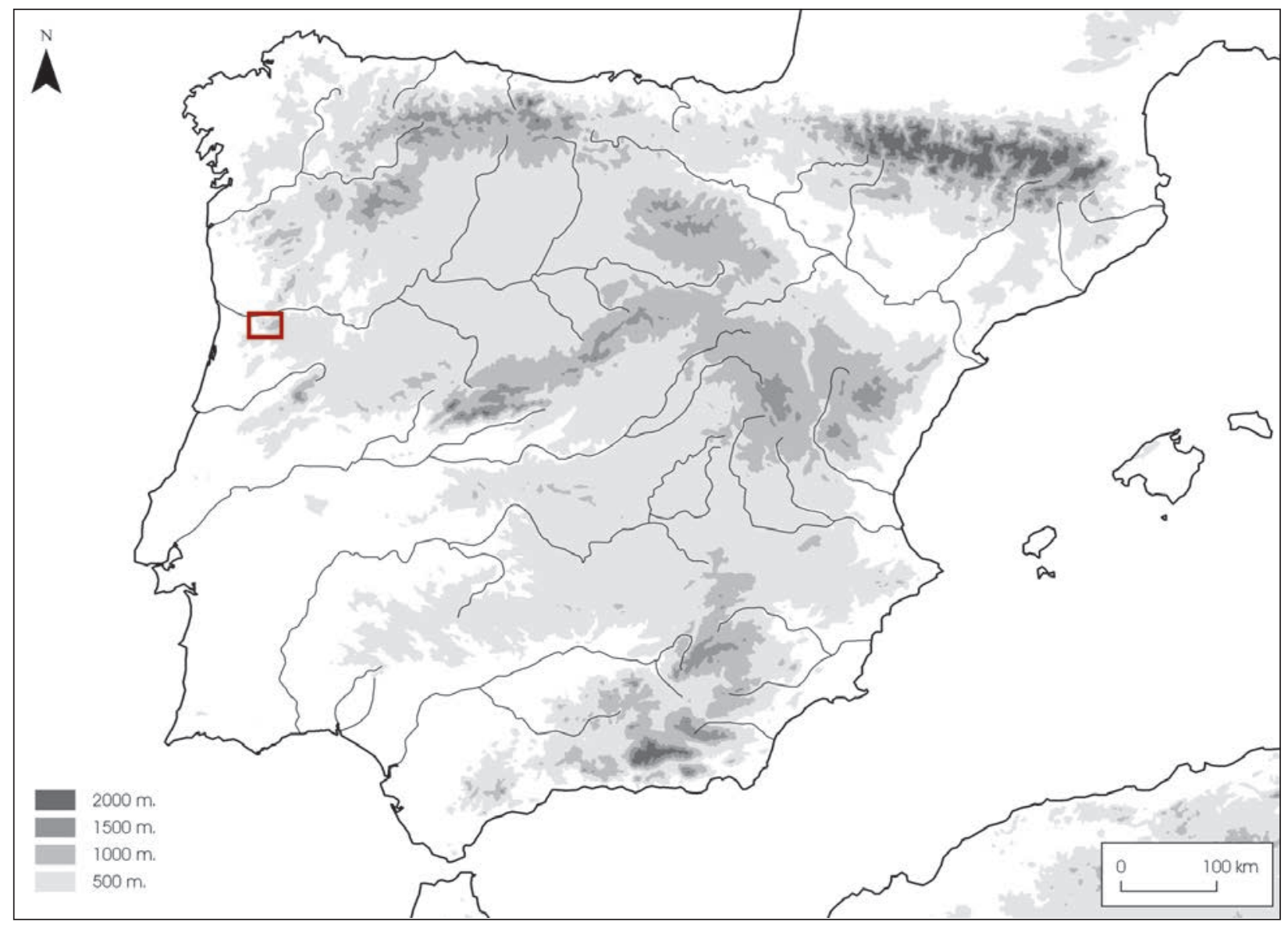

Figura 1. Localização peninsular da serra do Montemuro.

de geográfica bem definida: o rio Douro, a norte; o rio Paiva, a oeste e sudoeste; o rio Varosa (com o troço terminal do seu afluente Balsemão), e o rio Pombeiro / Vidoeiro, limitam-na respectivamente a este e a sudeste.

Geomorfologicamente corresponde a um "bloco tectónico levantado em relação ao planalto da Nave e balançado para noroeste, em direcção ao vale do Douro" (Ferreira, 2004: 104). Trata-se de montanha de média / elevada altitude (alt. máx. de 1381 metros no v. g. Montemuro), fundamentalmente granítica, com algumas manchas importantes do designado "complexo xisto-grauváquico", sobretudo a leste, a sul e sudoeste do maciço, para além das rochas filonianas, de que se destaca o quartzo, nomeadamente entre Monteiras e Mouramorta (Schermerhorn, 1980). Para leste do maciço a platitude é generalizada. São já os planaltos que se desenvolvem em torno dos níveis culminantes da Nave ("serra da Nave"), relacionáveis com a "superfície fundamental" dos "planaltos centrais", tal como foi definida por A. Brum Ferreira (1978: 241), uma ou outra vez pontuada por relevos que não ultrapassam muito os 1000 metros de altitude, sobretudo no sector norte.

A cobertura vegetal do maciço é contrastante, atendendo, quer à altitude e ao regime pluviométrico, opondo as vertentes e o fundo dos vales, mais arborizados e verdejantes, ao planalto, cuja vegetação é esparsa, essencialmente arbustiva e rasteira, quer ao substrato (granitos / xistos e grauvaques), a que se liga a potencialidade dos solos, índices de erosão, etc.; o contraste é também marcado entre as encostas viradas ao Paiva - pelo menos até à Ermida - , com importantes manchas de pinhal, a que se associam várias espécies de carvalho e o castanheiro, e as que se relacionam com o Douro, com este último, a par do sobreiro e do pinheiro, e outras arbóreas adaptadas às condições climáticas específicas do vale do Douro (oliveira, amoreira, nogueira, vinha, etc.).

O povoamento é concentrado, com tendência para a dispersão junto ao vale do Paiva. Os solos são pouco espessos, frequentemente ausentes, sobretudo nas áreas de relevo mais acentuado. A propriedade é de pequenas dimensões. A economia é fundamentalmente agropastoril, de subsistência. Uma parte importante do território está ocupada com matas e incultos, estes até há pouco utilizados extensivamente como baldios, principalmente para a criação de gado miúdo (ovelhas e cabras, sobretudo aquelas). A transumância dos gados das vizinhanças da serra da Estrela (Nelas, Santa Comba, Carregal do Sal, Canas de Senhorim, Oliveira do Hospital, etc.), em direcção ao Montemuro, seguindo trajectos há muito definidos, era prática corrente até há pouco tempo (Girão, 1940, 1951; Ribeiro, 1948; Dias, 1951, 1965; Medeiros, 2000). 
O povoamento do Montemuro atinge altitudes muito elevadas, a que não será alheio o regime pluviométrico, com consequências ao nível da agricultura e das pastagens, do coberto vegetal, do processo de formação de solos, etc., a que se associam outras condições favoráveis, como o carácter pouco acidentado do relevo e a existência de extensos "vales largos", com solos espessos, adequados às culturas de montanha, condições que permitiram "a estreita associação da agricultura com a criação de gado" (Ribeiro, 1948: 334).

Em termos administrativos a serra do Montemuro insere-se maioritariamente nos concelhos de Castro Daire, Cinfães e Resende, mais limitadamente, nos concelhos de Arouca, a este, e de Lamego, a oeste.

\section{BREVE ESTADO DA INVESTIGAÇ̃̃o}

Em 1940 Amorim Girão, em monografia que dedicou à serra do Montemuro, espantava-se com o desconhecimento geográfico que então se registava do conjunto de relevos que constituem o maciço. Trata também neste trabalho da ocupação do território ao longo do tempo. A presença humana mais antiga limitava-se a muito pouco, circunscrevendo-se a alguns tumuli da Senhora da Ouvida, o "castro" onde hoje assenta a vila de Castro Daire, uma ou outra inscrição romana (Ponte Pedrinha, Castro Daire) e, sobretudo, o enigmático sítio das Portas do Montemuro (Castro Daire / Cinfães), que, pouco convincentemente, atribuía aos povos castrejos. Com mais pormenor e interesse analisa igualmente a ocupação medieval, partindo das Inquirições de 1258 (Girão, 1940). As referências arqueológicas anteriores a 1940 são, de facto, muito reduzidas, limitando-se a achados avulsos, provenientes de sítios localizados nos concelhos de Cinfães e de Castro Daire. O Archeologo Portuguez, pela mão de José Leite de Vasconcelos, insere algumas destas notícias, que se reportam principalmente a objectos e jazidas do período da "romanização" e alta Idade Média (Vasconcelos, 1897-13, 1927); outros achados, daqueles períodos e da Idade do Ferro são relatados por João Gomes de Oliveira Guimarães, alguns dos quais depositados no Museu Arqueológico da Sociedade Martins Sarmento (Guimarães, 1900).

O conhecimento da ocupação antiga do relevo permaneceu bastante limitado até há pouco. É certo que nunca aqui foram desenvolvidas prospecções sistemáticas que visassem o inventário de sítios arqueológicos. Ainda assim devemos referenciar os trabalhos realizados no âmbito de um projecto dirigido por Eduardo Jorge Lopes da Silva, centrado no sector norte do Montemuro - concelhos da margem esquerda do Douro (Castelo de Paiva, Cinfães, Resende) - , mas cujos resultados permanecem em grande parte inéditos (Silva e Cunha, 1988-94; Silva et al., 1996; 1997), bem como o inventário que tem por base o vale do Bestança (Pinho, 1996, 1997, 2000; Lima, 2000) e a parte serra- na do concelho de Arouca (freguesia de Alvarenga), que foi também criteriosamente inventariada por Fernando Pereira da Silva (Silva, 2004; Silva e Silva, 1994). O sector do Montemuro inserto no concelho de Castro Daire mereceu também referenciação na monografia do concelho (Correia et al., 1995), ainda que com tratamento diferenciado relativamente a alguns períodos, muitas vezes com base em informações orais não verificadas no terreno. Os momentos mais recentes, como a Proto-história e o período da ocupação romana mereceram abordagens mais desenvolvidas em sínteses recentes de carácter regional (Silva, A. C. F., 2007; Vaz, 1997).

A realidade arqueológica da serra do Montemuro, a partir dos trabalhos de projecto, ou dos estudos de impacte ambiental que derivaram do aproveitamento da energia eólica, é bem diversa, embora circunscrevendo-se fundamentalmente a trabalhos de inventário; é também limitada a divulgação científica desses resultados. Um desses projectos, coordenado por um dos autores (DJC), revelou um grande número de jazidas; relativamente ao período pré-histórico destacam-se os tumuli, sejam do Neolítico, sejam já da Idade do Bronze, quer nas faldas da serra, quer das plataformas mais elevadas. A ocupação da serra do Montemuro remonta seguramente ao Neolítico médio-final, ou seja, desde pelo menos meados do $\mathrm{V}$ milénio a. $\mathrm{C}$. (Santos e Cruz, 2013). Contrariamente à afirmação de A. Girão não podemos hoje dizer que "debalde procurámos quaisquer vestígios de monumento megalítico pelas suas esplanadas onde a água não falta, e poucas são as posições castrejas que nela pudemos com segurança localizar" (Girão, 1940: 63).

Nos planaltos da Nave (níveis culminantes e vale do Paiva) são igualmente reconhecidas jazidas, quer na bibliografia mais antiga (Moreira, 1924; Vasconcelos, 1933; Gama, 1940; Cortez, 1951, 1952; Leisner, 1998; etc.), quer em trabalhos realizados no âmbito de projectos de investigação mais recentes. Tal como no Montemuro, também aqui se inventariaram algumas centenas de tumuli, de diferentes períodos (Neolítico / Bronze Final), um ou outro recinto muralhado, menires, estátuas-menires, estações de arte rupestre, etc. (Cruz, 2001; Cruz e Santos, 2011; Santos, 2000; Valinho, 2003) cuja cronologia por vezes se estende até ao final da Idade do Bronze (Cruz, 1998; Cruz e Vilaça, 1999; Cruz, 2000). De qualquer modo, a identificação de sítios de habitat, sobretudo para os períodos mais antigos, é ainda limitada. Este tipo de vestígios é mais evidente a partir do Calcolítico, em especial os de finais da Idade do Bronze e a Idade do Ferro; outros testemunhos dizem já respeito ao período da ocupação romana e da alta Idade Média (Vieira, 2004, 2006); do povoamento da Idade do Bronze destacamos aqui os trabalhos integrados em projectos de investigação que se desenvolveram nos sítios de Canedotes (Vila Nova de Paiva), datado dos finais da Idade do 
Bronze (Vilaça e Cruz, 1995; Canha, 2002; López Sáez et al., 2000), e do Castro de Vila Cova-àCoelheira (Vila Nova de Paiva), cuja ocupação se centra em curto período dos inícios da Idade do Ferro (Loureiro et al., 2006; Mendes, 2009; López-Sáez et al., 2002-03); outros trabalhos, ainda inéditos, reportam-se ao sítio do Muro (Moimenta da Beira).

\section{IDENTIFICAÇÃO DOS ACHADOS}

\subsection{Metodologia e descrição}

Como referimos antes, este trabalho partiu do estudo arqueométrico de um machado de alvado e duplo anel que, genericamente, sabemos ser proveniente "Das abas da Serra de Montemuro (comprado em Évora)"4; esse estudo inicial alargou-se a uma análise mais ampla que envolveu os machados metálicos existentes na região, aos quais se associou ainda o conhecido molde em bronze de machados de talão de duplo anel de Vila Boa (Castro Daire) e uma "lâmina serrilhada" atribuída à serra do Montemuro, esta praticamente inédita.

Como nota de fundo, importa dizer ainda que, face à limitada informação existente, a contextualização dos vestígios mais não é que um primeiro esboço da ocupação humana do Montemuro e áreas limítrofes.

A metodologia de trabalho, alicerçada em pesquisa bibliográfica, permitiu associar ao estudo testemunhos vários que se repartem pelos actuais concelhos de Cinfães, Castro Daire, Vila Nova de Paiva, Tarouca e Moimenta da Beira. Além do principal propósito de identificação dos artefactos metálicos, foi efectuada uma leitura da distribuição espacial dos mesmos bem como a sua possível inter-relação com outros elementos arqueológicos da região.

Recorrendo aos incontornáveis trabalhos de Savory (1951), MacWhite (1951), Junghans, Sangmeister e Schröder (1968), Hardaker (1976), Monteagudo (1977) e Coffyn (1985), revimos todas as peças associadas a esta área geográfica, não sem algumas dificuldades. A caracterização dos artefactos, bem como a sua verdadeira quantificação, encontram-se algo perturbadas por informação nem sempre precisa em determinados casos. Entre as principais limitações, destacase a falta de rigor geográfico ou toponímico, aquando da localização da proveniência dos artefactos, ou ainda

4 Informação manuscrita no desenho do machado efectuado por R. Gameiro em 1906 (cf. adiante).

5 Simplificou-se a atribuição da tipologia por considerarmos irrelevantes muitas das divisões do autor. Para o caso dos machados de talão pode ver-se também Díaz-Andreu (1988).

6 Lamas de Moledo, onde se documentou a célebre inscrição que referencia a comunidade dos "Magareaicoi". Segundo a leitura de J. L. I. Vaz (1990: 285), «Rufino e Tiro determi- a nem sempre cuidada descrição de atributos básicos, como a dimensão ou o peso dos objectos. De igual modo, considerando que esta pesquisa nasceu de uma análise arqueométrica, assinala-se a escassez deste tipo de estudos, que condicionam a caracterização tecnológica e cronológica das restantes produções.

Não obstante as insuficiências, comuns em trabalhos baseados em achados e publicações antigas, foi possível documentar para as áreas do Montemuro e região do Alto Paiva (planalto da Nave e bacia superior do Paiva) (Fig. 2), treze registos de várias tipologias e cronologias, indicadores da produção, circulação e amortização de artefactos relacionados com a cadeia metalúrgica, desde o Calcolítico.

De modo a facilitar a leitura da informação, agrupam-se os objectos numa tabela (Fig. 3), identificandose, com base nos dados existentes, o seu contexto de achado e actual depósito, bem como as principais características físicas e tipologia, seguindo-se neste aspecto os trabalhos de Monteagudo para os machados peninsulares $(1977)^{5}$.

Posto isto, os treze objectos metálicos repartem-se de acordo com as seguintes tipologias: i) três machados planos; ii) cinco machados de talão; iii) três machados de alvado; iv) um molde de machados de talão; v) uma lâmina de gume serrilhado.

\subsection{Breve contextualização arqueológica}

\subsubsection{Outeiro da Maga/ Castelo da Manha (Moledo, Castro Daire)}

O Outeiro da Maga (Alto da Maga, na cartografia) localiza-se no sector su-sudeste do concelho de Castro Daire; dista cerca de $2 \mathrm{~km}$ de Moledo, que fica a sudeste, e $2,15 \mathrm{~km}$ da povoação da Moita, localizada a oés-sudoeste; Lamas, a sudoeste, dista do sítio cerca de 2,5 $\mathrm{km}^{6}$; o local, com a altitude máxima de $705 \mathrm{~m}$, é sobranceiro à ribeira da Moita/ ribeiro do Corgo, afluente do rio de Mel, subsidiário do rio Vouga.

O sítio é referenciado no manuscrito de Manoel Botelho Ribeiro Pereira (séc. XVII), intitulado Dialogos Moraes e Politicos, publicado em 19557; este erudito refere-se à "Maga [...], em cuja altura ha vestígios, e signais de muros de pedra tosca com sua barbacã" (p. 125); nas Memórias Paroquiais de 1758, relativamente à freguesia de Moledo, também se diz que: "E

naram (que os) Veaminicori oferecessem ancom Iamaticom a Crougai (protectora dos) magareaicoi e os Petravioi radom porcom a Lovea (protectora dos) Caelobricoi». Veja-se breve resumo das diferentes opções interpretativas em Armada (2015: 145-146).

7 Obra escrita entre os anos de 1630 e 1636, foi publicada, a partir de cópia do século XVIII, como volume autónomo da revista Beira Alta (vol. XIV, fasc. 1-2). 


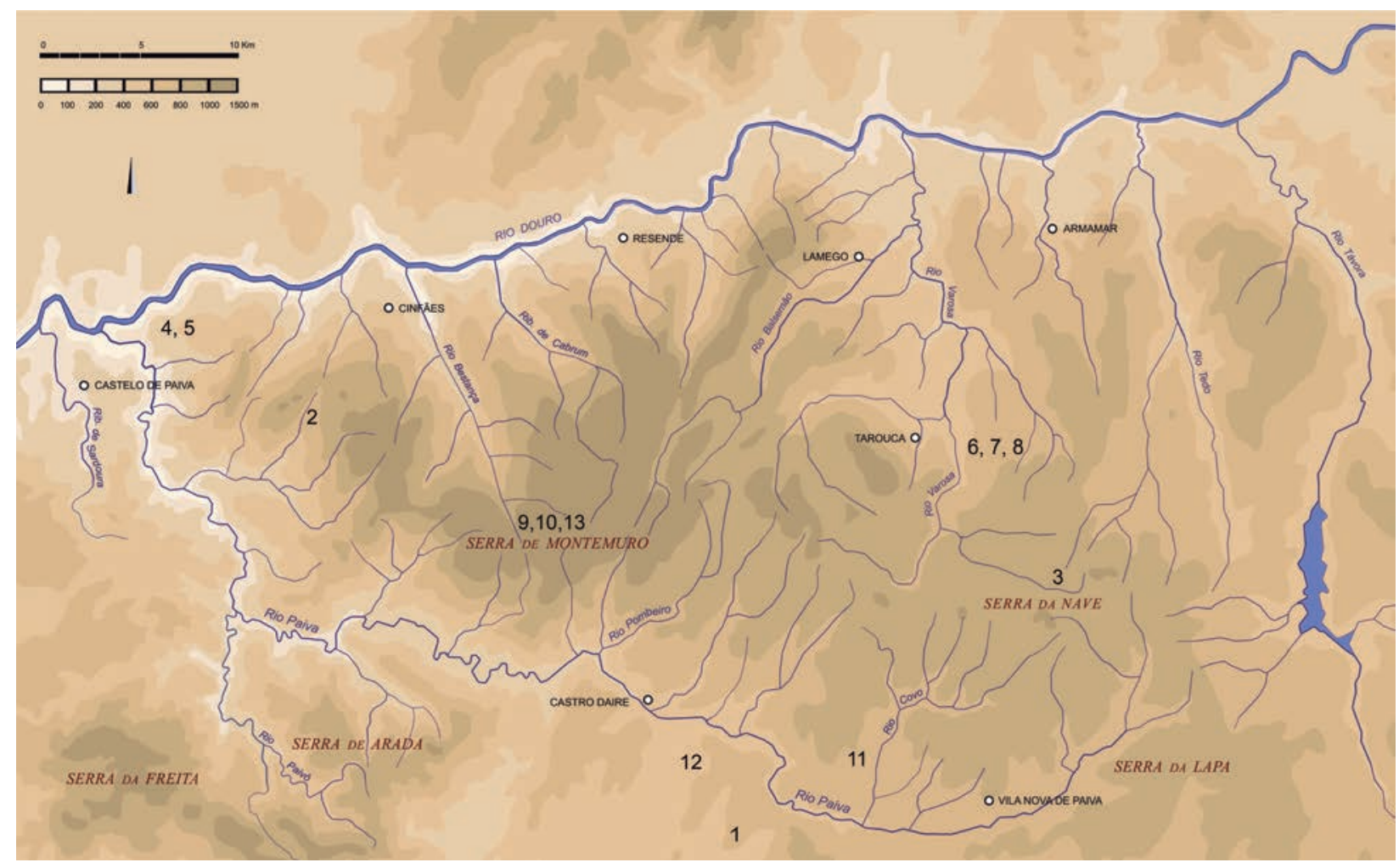

Figura 2. Área de estudo e localização dos achados: Serra do Montemuro, Alto Paiva e interflúvio Paiva-Vouga (localizações aproximadas). 1- Outeiro da Maga; 2- Ervilhais; 3- Orca de Seixas; 4 e 5- Retorta; 6, 7 e 8- Castro de Mondim da Beira; 9, 10 e 13- Serra do Montemuro; 11- Castro de Vila Cova à Coelheira; 12- Vila Boa.

para a parte do Norte deste lugar de Moledo fica outro monte que chamam a serra de Maga, aonde está outro oiteiro que chamam o Castelo de Menha ou o Castelo de Maga, adonde se descobrem huns pedaços de parede que em partes terão ainda hoje sete ou oito palmos [c. 1,54 m-1,76 m] de altura e parede forte" (Capela e Matos, 2010: 205). Este "muro", interpretado por Russell Cortez como a muralha do povoado (1951: 164-165) seria então bastante destacado; hoje resume-se, na maior parte dos tramos, à base, ou está mesmo ausente.

O Castro do Corgo da Maga foi escavado nos finais dos anos 40 por Russell Cortez (1951: 164-165, 181; 1952: 210, 228, est. III). Destas escavações resultou o achado de um machado plano (Fig. 4), aparentemente associado a um fundo de cabana, datado do "Eneolítico": "Embora os fundos de cabana do Corgo da Maga pertençam já aos primórdios do eneolítico, com um machado plano de cobre, espero que, com o adiantamento das escavações, nos surjam elementos que iluminem melhor aqueles tempos em que principiou, duma forma mais consciente, a exploração huma-

8 Por informação oral sabemos da existência de outros materiais metálicos, nomeadamente de uma "seta verde", resultantes de escavações clandestinas - uma das quais há pouco mais de 10 anos, realizada num abrigo sob rocha existente na área do povoado - , pretensamente na posse de na da natureza, nos seus sectores: mineral, vegetal e animal" (Cortez 1952: 228). Trabalhos recentes de prospecção permitiram a recolha de materiais cerâmicos, datáveis, sobretudo, do final da Idade do Bronze (Loureiro et al., 2006: 109); antes, outras recolhas referenciam também cerâmica e elementos de moagem relativa à ocupação da Idade do Ferro (Vaz, 1995: 102103; 1997: 27; Pedro, 1995: 14, est. LX-4) ${ }^{8}$.

\subsubsection{Ervilhais (Nespereira, Cinfães)}

Em Ervilhais (Nespereira, Cinfães) referencia-se genericamente o achado de um machado plano (Junghans et al., 1968: 28-29, n 1559; Monteagudo, 1977: 40, Taf. 7, 136) ${ }^{9}$. Esta pequena aldeia, como também o lugar do Castelo, localizam-se aproximadamente a sudeste do Monte da Senhora do Castelo; trata-se de um relevo alongado, orientado de NE para SO, repartindo-se entre as freguesias de Nespereira e de Santiago de Piães; no topo do relevo denotam-se duas elevações: Gia (1025 m), a nordeste, que suporta o marco geodésico com este nome; e o Alto do Facho (1028 m), a sudoeste; os vestígios arqueológicos aqui

elementos das povoações vizinhas, mas que não foi possível observar.

9 Em ambos os autores este sítio aparece com a grafia "Ervilhas". 


\begin{tabular}{|c|c|c|c|c|c|c|c|c|c|c|c|c|c|}
\hline 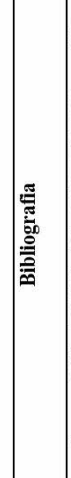 & 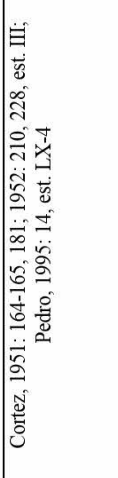 & 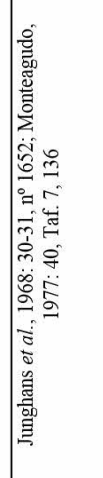 & 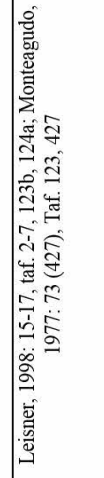 & 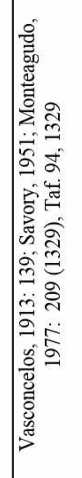 & 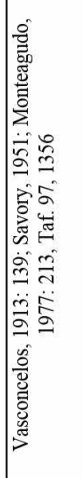 & 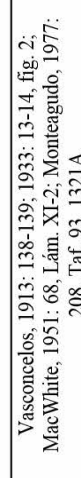 & 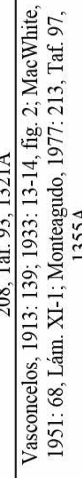 & 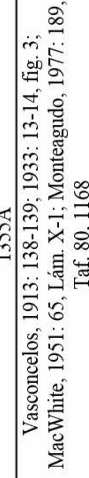 & 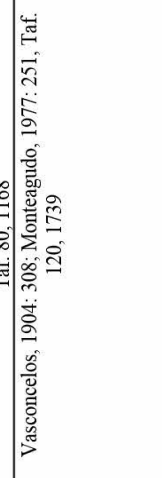 & 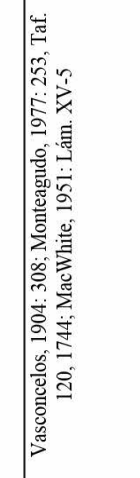 & 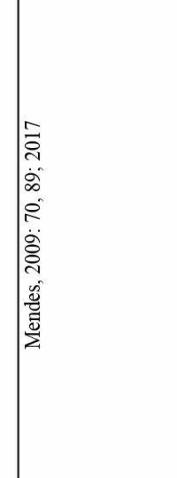 & 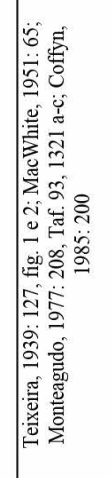 & 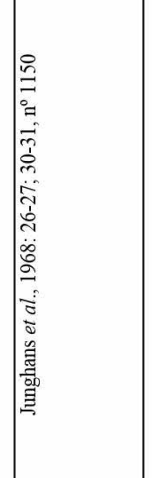 \\
\hline 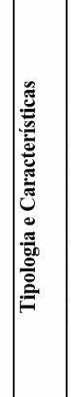 & 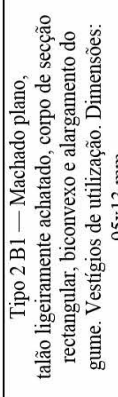 & 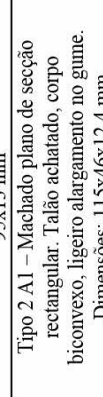 & 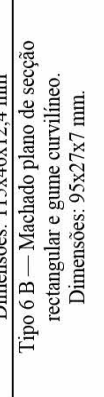 & 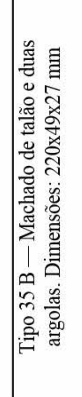 & 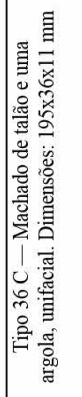 & 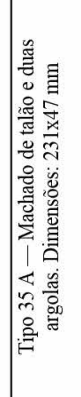 & 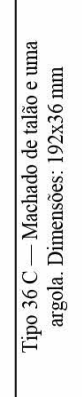 & 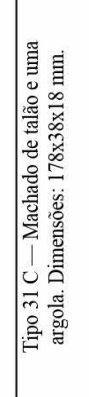 & 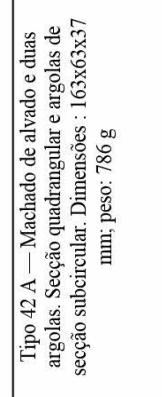 & 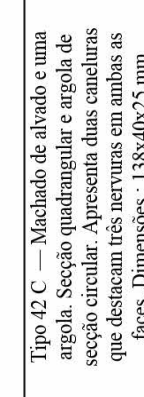 & 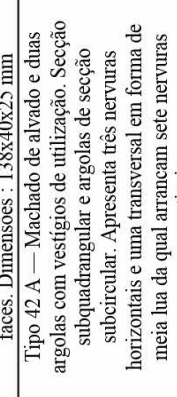 & 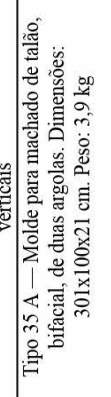 & 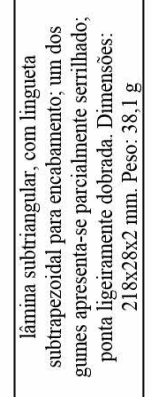 \\
\hline |c: & 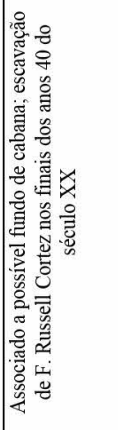 & 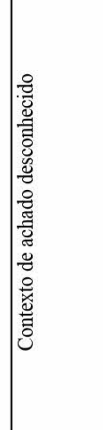 & 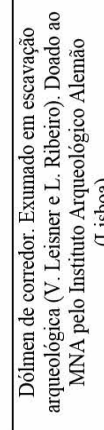 & 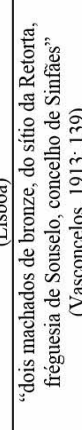 & 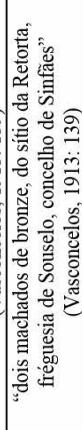 & 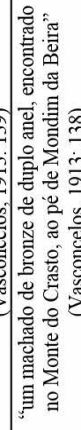 & 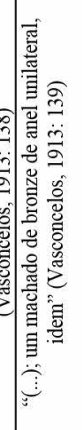 & 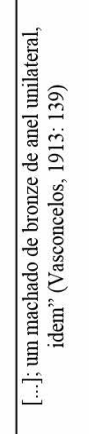 & 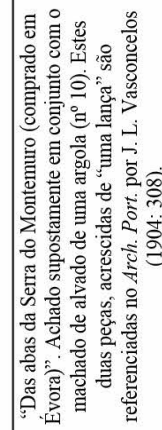 & 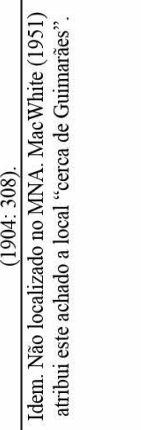 & 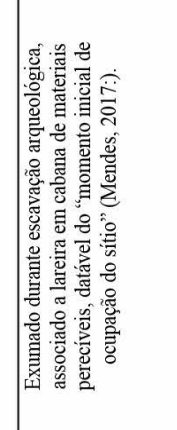 & 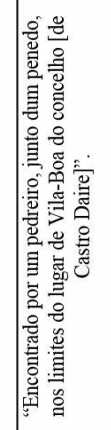 & 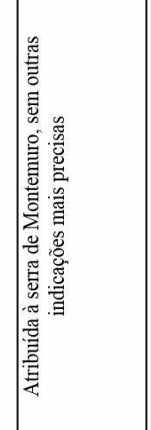 \\
\hline 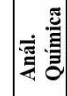 & $\stackrel{\circ}{\dddot{2}}$ & 贯 & 急 & 送 & 腪 & 逡 & 逢 & 涭 & 兒 & 辣 & 鼠 & 童 & 貣 \\
\hline 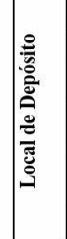 & 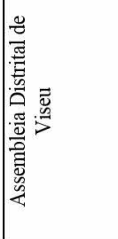 & 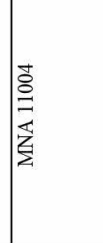 & 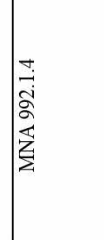 & 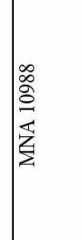 &  & 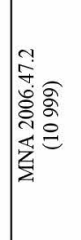 & 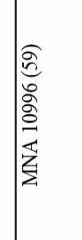 & 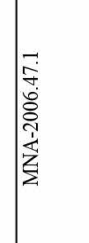 & 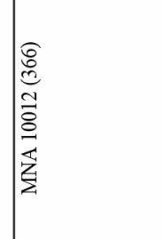 & 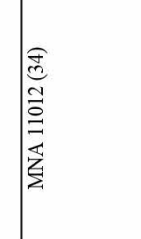 & 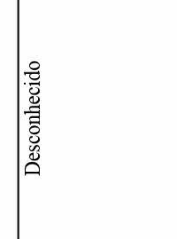 & 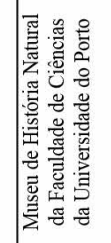 & 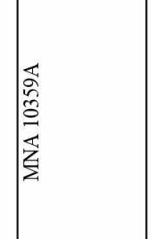 \\
\hline 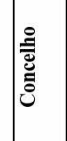 & $\mid$ & 送总 & 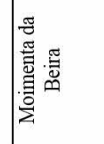 & 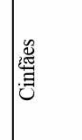 & 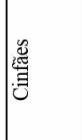 & $\begin{array}{l}\text { 畄 } \\
\text { 意 }\end{array}$ & 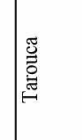 & 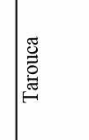 & 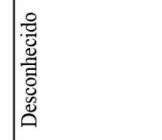 & 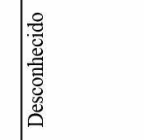 & 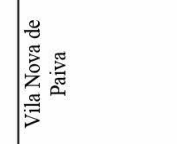 & 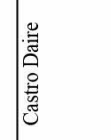 & 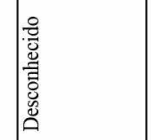 \\
\hline 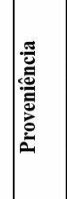 & $\mid$ & 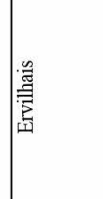 & 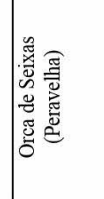 & 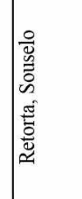 & 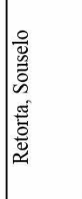 & 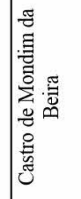 & 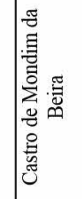 & 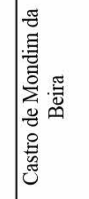 & 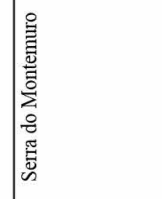 & 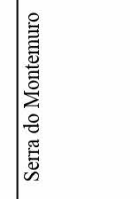 & 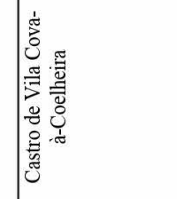 & 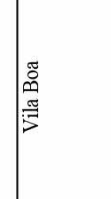 & 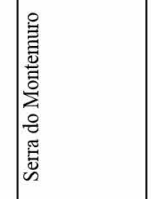 \\
\hline 育 & 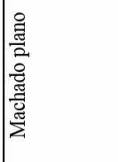 & 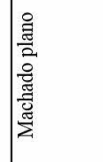 & 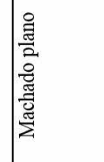 & 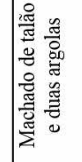 & 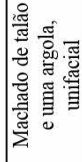 & 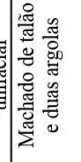 & 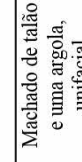 & 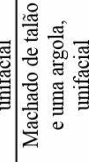 & 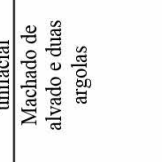 & 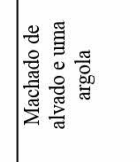 & 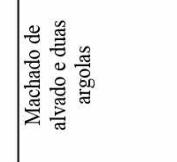 & 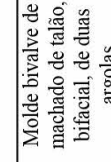 & 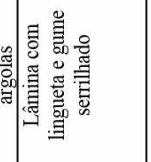 \\
\hline \& & - & ه & $m$ & न & in & 10 & $\sim$ & $\infty$ & a & $\subseteq$ & $=$ & $\approx$ & $\approx$ \\
\hline
\end{tabular}

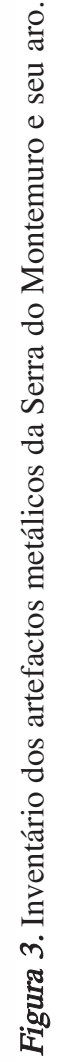




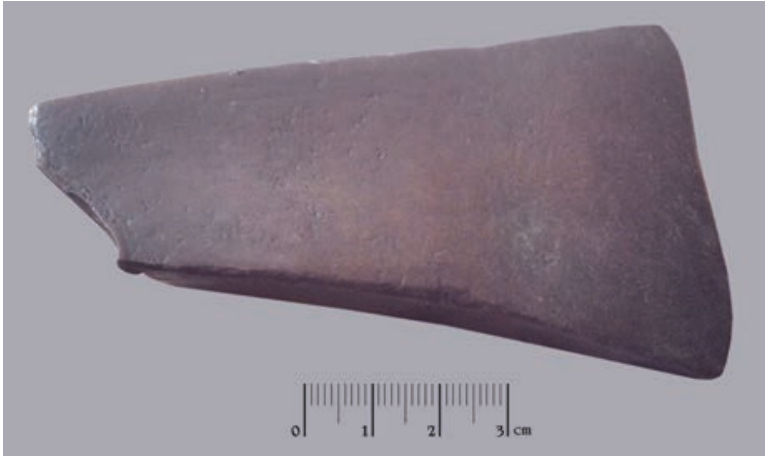

Figura 4. Machado plano do Corgo da Maga (Moledo, Castro Daire)

(fotografia: Pedro Sobral de Carvalho).

identificados, como também no vale de um afluente da ribeira de Sampaio (desde Ervilhais a São Cristóvão de Nogueira) são sobretudo de idade medieval (Lima, 2000: 61-63), destacando-se uma cerca medieval, cerâmicas, argamassa, etc., e na base Este do relevo, vestígios de uma via medieval - carril veterem - eventualmente com origem mais antiga; na Idade Média este morro terá suportado o castelo que capitaneou a terra de Sanfins (antigo concelho, hoje fazendo parte da freguesia de Santiago de Piães) - civitas Sancto Felici, na documentação medieval; em tempo recente os espaços entre monólitos foram aproveitados para a construção de uma pequena capela rupestre onde se guarda uma imagem de Nossa Senhora. A bibliografia referencia muito genérica e imprecisamente materiais de cronologia pré-histórica nos sítios do Alto do Castelinho e Roda de Merouço (Nespereira) e Castelo Velho (Ervilhais, Nespereira) (Pinho, 2000: 15). No terreno não há disso evidências. De qualquer modo, referenciamos aqui uma ficha da base de dados da Direção-Geral do Património Cultural - Endovélico - que menciona o achado?/ escavação?, no alto da Gia (na extremidade nordeste do relevo) de "fragmentos cerâmicos, integráveis na Idade do Bronze, uma conta de colar verde perfurada, possivelmente de variscite, um fragmento de lâmina de sílex"10. Por fim, não muito longe de Ervilhais (para leste, a pouco mais de 1 $\mathrm{km}$ ), situam-se os quatro tumuli de Chão do Brinco (Nespereira); os monumentos 1 e 2 foram escavados por E. J. L. da Silva (1993, 1994); o dólmen 1 de Chão do Brinco, de idade neolítica, revelou uma ou mais reutilizações tardias - cerâmica campaniforme, uma peça em ouro, cinco lajes gravadas, das quais se conhece uma "estela" e uma outra, de menores dimensões, com um antropomorfo esquemático gravado - , datáveis dos finais do III milénio a. C. (Silva, 1993; Santos e Cruz, 2013).

10 Base de dados Endovélico (dgpc): CNS: 14523. Monte da Senhora do Castelo/GIA (Santiago de Piães, Cinfães). Desconhecemos a origem da informação e localização deste espólio, embora o texto da ficha seja de um de nós (DJC), a
O machado plano referenciado como de "Ervilhais" (Fig. 5, n. ${ }^{\circ}$ 136) é um achado avulso, não sendo possível relacioná-lo, por enquanto, com um sítio específico desta área mais a sul do concelho de Cinfães, seja habitacional, sepulcral, ou outro. Aparentemente o sítio da Gia parece ter prestado vestígios datáveis do Calcolítico; o dólmen 1 de Chão do Brinco, relativamente perto da povoação de Ervilhais, forneceu igualmente artefactos de cronologia similar.

\subsubsection{Orca de Seixas (Peravelha, Moimenta da Beira) ${ }^{11}$}

Trata-se de um dólmen de corredor, de grandes dimensões (no contexto do megalitismo da Beira Alta), implantado em esporão sobranceiro à "Chã das Lameiras"; quer nesta superfície de terras alagadiças (sobretudo no rebordo), quer nos relevos que definem esta grande depressão (Leomil, 1008 m; Laje Branca, 1012 m; Nave, 1016 m; etc.), foram construídas algumas dezenas de tumuli, uns contendo dólmenes, datáveis do Neolítico médio-final, outros, de que não conhecemos as estruturas internas e cronologia, outros ainda com cistas datáveis da Idade do Bronze; ocorrem, sobretudo nas cumeadas, tumuli de pequenas dimensões, muito baixos, de cronologia imprecisa dentro da Idade do Bronze, talvez já dos finais da Idade do Bronze. Foram igualmente aqui identificadas três estátuas-menires, cuja cronologia se inserirá nos finais do Calcolítico/ inícios da Idade do Bronze (Cruz, 2001; Cruz e Santos, 2011).

O monumento foi escavado em 1968 por Vera Leisner e Leonel Ribeiro; os resultados foram publicados postumamente (Leisner, 1998: 15-17, Taf. 2-6, 123b e 124a). O dólmen foi intervencionado em 1999 pela empresa Arqueohoje, Ld. ${ }^{\text {a }}$ - no âmbito do projecto de investigação de um dos autores (DJC) - , mas visando sobretudo a consolidação de estruturas e valorização. Esta intervenção incluiu a escavação da área da entrada do dólmen - átrio, corredor intratumular, estrutura pétrea de condenação - , que permanecia intacta; foram aqui recolhidas amostras de material vegetal que permitiram a definição da cronologia da utilização primária do monumento e encerramento do dólmen; antes, já Vera Leisner tinha procedido no sentido da datação do enchimento da câmara (GrN-5734: 4900 \pm 40 BP); as quatro datações realizadas com amostras do átrio permitem definir a utilização final, prévia ao encerramento com a estrutura de condenação, que podemos situar genericamente no primeiro terço do IV milénio a. C. (Cruz, 2001: 376-377, 145-150, 237).

que foram acrescentados aqueles dados.

11 Erroneamente, Monteagudo (1977: 73) localiza a Orca de Seixas no distrito da Guarda. 


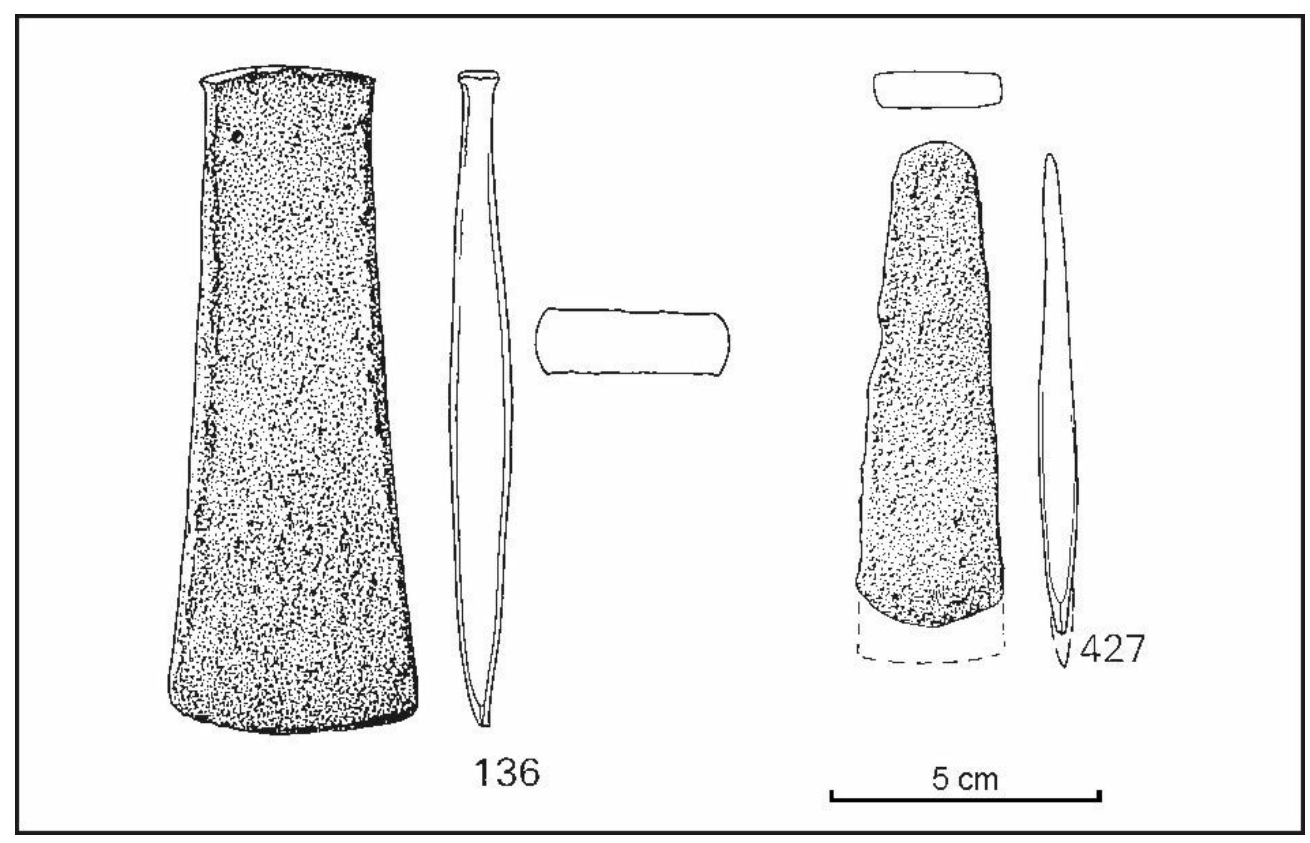

Figura 5. Machados planos de Ervilhais (Nespereira, Cinfães) (136) e Orca de Seixas (Peravelha, Moimenta da Beira) (427) (desenhos de Monteagudo, 1977).

A Orca de Seixas é um dólmen de câmara de planta poligonal de nove esteios e corredor longo ( $7 \mathrm{~m}$ de comprimento), diferenciado daquela em planta e altura; a entrada do corredor era obliterada por uma laje pouco espessa ("porta"). Os trabalhos de escavação iniciais revelaram espólio lítico e cerâmico datável do período de construção e utilização primária (micrólitos geométricos - segmentos e triângulos - , fragmentos de lâminas, machados de pedra polida, vasos cerâmicos de corpo esférico, etc.); o dólmen foi reutilizado mais tarde, já no Calcolítico / Bronze Antigo, integrando o machado plano em cobre em análise neste trabalho (Fig. 5, n. ${ }^{\circ}$ 427) e uma ponta em cobre de tipo Palmela, mas a que podemos associar, talvez, os dois vasos campaniformes ("pontilhado de bandas"), um "braçal de arqueiro", um "disco", em cerâmica, com duas perfurações na parte central, vários vasos troncocónicos, etc. (Leisner, 1998: 15-17, Taf. 2 a 6). Particular interesse assumem as cinco peças líticas (martelos e bigorna) que, em associação com as metálicas, permitem integrar esse contexto sepulcral no grupo das sepulturas de artesãos do metal (Armbruster, 2010).

\subsubsection{Retorta (Souselo, Cinfães)}

Do sítio da Retorta (Souselo, Cinfães) provêm dois machados de talão, um unifacial de uma argola (Fig. 6, n. ${ }^{\circ}$ 1356), o outro de duas argolas (Fig. 6, n. ${ }^{\circ}$ 1329); os achados são referenciados por J. Leite de Vasconcelos

12 O Castro de Sanfins é muitas vezes colocado na área administrativa da freguesia de Paçô (Moimenta da Beira), mas, de facto, cartograficamente (Carta Militar de Portugal, esca-
(1913: 139), que os adquiriu para o Museu Etnológico Português, depois de terem passado pelas mãos de dois negociantes, um de Penafiel, outro de Braga, onde foram comprados. O "Livro de Entradas" do Museu, onde estão registados com os nos 3061-10989 e 306210988, refere o seu ingresso em Julho de 1910. Não se conhecem outros dados que permitam a contextualização destes objectos (Savory, 1951; Monteagudo, 1977), os quais poderiam corresponder, a título meramente hipotético, mas não descartável, a um contexto de depósito. A freguesia de Souselo corresponde à área geográfica mais a noroeste do concelho de Cinfães, na confluência dos rios Douro e Paiva.

\subsubsection{Castro de Mondim da Beira (Mondim, Tarouca $)^{12}$}

Povoado fortificado implantado sobre relevo proeminente localizado a nascente de Mondim de Cima (Tarouca) e a sudoeste da povoação de Sanfins (Moimenta da Beira); na plataforma superior existe um marco geodésico (Mondim, $855 \mathrm{~m}$ ). O relevo é também localmente referenciado como "Cabeço do Castro", "Outeiro do Castro", "Pico do Castro", "Monte do Castro" e "Crasto" (Moreira, in Vasconcelos, 1933: 23). O sítio é já referenciado no século XVIII: i) Frei Manuel da Rocha, autor de Portugal Renascido (Coimbra, 1730), refere-se ao "Castello" situado sobre o lado direito do rio Varosa, la de 1: 25 000, fl. 148 (Moimenta da Beira), 3. ${ }^{\text {a }}$ ed., 1997), o relevo onde se implanta o povoado fortificado situa-se na freguesia de Mondim da Beira (Tarouca). 
sobranceiro à "villa de Mondim", "onde se acharam nestes anos proximos varios instrumentos de guerra, como são, ferros de lança, martelos, e outros mais, entre os quais se acharam tambem algumas moedas dos Emperadores Romanos, que conservo em meu poder, e entre elas uma de Constantino Junior" (apud Vasconcellos, 1933: 29); ii) nas Memorias Paroquais de 1758, o pároco de Mondim da Beira referencia que "Está para a parte do Nascente huma serrinha na distancia da villa [Mondim] pouco mais de quarto de legoa, a que chamam Crasto de Mondim" (Capela e Matos, 2010: 580-581); iii) igualmente o pároco de Paçô (Moimenta da Beira) se lhe refere: "Entre o Meio Dia e Poente onde tem principio o valle em que está situada a freguezia [Paçó] há hum monte alto, chamado vulgarmente o Crasto, em cuja cimalha está hum torraplano em forma ovada, onde caberão dois regementos de soldados artifiozamente feito. Cercava em outro tempo a esta praça ou castello huma muralha de que ainda hoje em toda a circumferencia se observam os vestigios dos alicerces de pedras lavradas, de quoais muntas são triangulares. Deste muro em distancia de vinte paços e de mais em algumas partes se observam ruinas de outro segundo muro da mesma formatura, e por fora deste em distancia de quarenta e cincoenta passos se descobrem ainda vestigios de outro, com circumferencia correspondente aos dois primeiros" (Capela e Matos, 2010: 368).

Entre Agosto e Outubro de 1914, o Abade de S. João de Tarouca, Vasco Almeida Moreira, realizou aqui, a pedido de J. Leite de Vasconcelos, trabalhos de escavação arqueológica, quer na plataforma superior, quer entre muralhas e no sítio da Ranha - uma plataforma, mais baixa, que se desenvolve a norte do Castro, à distância de cerca de $150 \mathrm{~m}$. A estes trabalhos se refere na Monografia de Tarouca, de que é autor: "No extremo oriental do concelho, entre a freguesia de Mondim e a povoação de Sanfins, está o resto dum castro. É muito importante êsse castro, não só pela sua extensão e grandeza, pois deve medir aproximadamente 500 metros de circunferência, mas tambem pelos restos aí aparecidos. Procedendo a escavações nêle achamos muitos vestígios dos lusitanos, como casas com restos de cinzeiros, mós, objectos de cerâmica, machados de pedra polida, etc. Mais abaixo dêste cas-

13 As descrições e registos de J. L. de Vasconcelos (Vasconcelos, 1913b: 138-139; 1933: 13-14, figs. 2 e 3) correspondem apenas a dois machados. Eoin MacWhite (1951: 68) representa estes machados nas estampas X.1 (machado de talão com dois anéis) e XI.1-2 (machado de talão com um anel). A lâmina do machado de um anel teria resultado da junção de duas lâminas (aparentemente feitas em moldes diferentes, pois têm comprimentos diferentes e são de tipologias distintas), através de soldadura; teríamos assim dois machados monofaciais, unidos, dando origem a um machado bifacial de uma argola. Leite de Vasconcelos tro, numa colina sobranceira a Sanfins [Ranha], os mesmos vestígios se nos revelaram [...]" (Moreira, 1924: 28). J. Leite de Vasconcellos publica mais extensamente os resultados destes trabalhos (Vasconcellos, 1933: 13-60). Em resumo, o relevo terá tido uma ocupação que remontará, pelo menos, aos finais da Idade do Bronze, Idade do Ferro e Época romana, assinalando-se, relativamente à ocupação mais antiga, que "Os objectos de metal apareceram nas excavações a dentro da segunda muralha, à profundidade de 2m,50, havendo aí também cacos, lascas de pedra e vestígios de volantes de fusos, mas não tijolos nem vestígios de casas" (Moreira, in Vasconcelos, 1933: 25). Os materiais metálicos, em bronze, integram vários tipos de fíbulas - de codo, sub-tipo Huelva; anulares hispânicas; em "omega" - , algumas argolas, uma agulha, etc. (Vasconcelos, 1933: 45-47, figs. 50-52), de cronologia por vezes díspar, condizente com a ocupação alargada deste sítio; as fíbulas de codo foram reconstituídas e estudadas por Júlio Roque Carreira (1994: 82, fig. 9, 2 e 3).

Os três machados de talão, dois de uma argola (Fig. 6, n. ${ }^{\circ} 1168,1355 \mathrm{~A}$ ), outro de duas argolas (Fig. 6, n. ${ }^{\circ}$ 1321A), do Castro de Mondim são achados avulsos, anteriores às escavações do Abade Vasco Moreira, achados ocorridos em momentos distintos e realizados por pessoas diferentes; o(s) primeiro(s) encontrado(s) por pastor de Sanfins e o segundo por Manuel Brisido, de Mondim de Cima; as peças, provenientes "do Monte do Castro, ao pé de Mondim da Beira", foram oferecidas em 1910 ao Museu Etnológico por Américo Isidoro Augusto de Azevedo, natural de Mondim e conterrâneo de J. L. de Vasconcelos (Vasconcelos, 1913: 138-139; 1933: 13-14, figs. 2 e 3; MacWhite, 1951: 68, lám. X.1, XI.1-2; Monteagudo, 1977: 208, Taf. 93: 1321A; 213, Taf. 97: 1355A) ${ }^{13}$.

\subsubsection{Serra do Montemuro}

Dado como proveniente "Das abas da Serra do Montemuro (comprado em Évora)", conforme informação manuscrita no desenho efectuado por R. Gameiro em 1906 (Figs. 7, 8 e 6, n. ${ }^{\circ}$ 1739), o machado de alvado que analisámos faz parte do acervo do MNA (N. Inventário 11012) e terá integrado um conjunto de

refere-se a esta situação nestes termos: "De um dos bordos, ao lado da nervura transversal, sobressai uma asa semi-circular, e ao longo de cada um dos dois bordos, abrangendo esta asa, passa uma espécie de corda como vestigio da soldadura das duas metades que compõem a folha, e que haviam sido fundidas cada uma por sua vez" (1933: 14]. MacWhite (1951) e Monteagudo (1977) descrevem as duas lâminas que compõem este machado de talão de um anel separadamente, critério que seguimos neste trabalho. No MNA há apenas 2 machados, um de uma argola n 10996 e um de duas argolas n ${ }^{\circ} 10999$. 

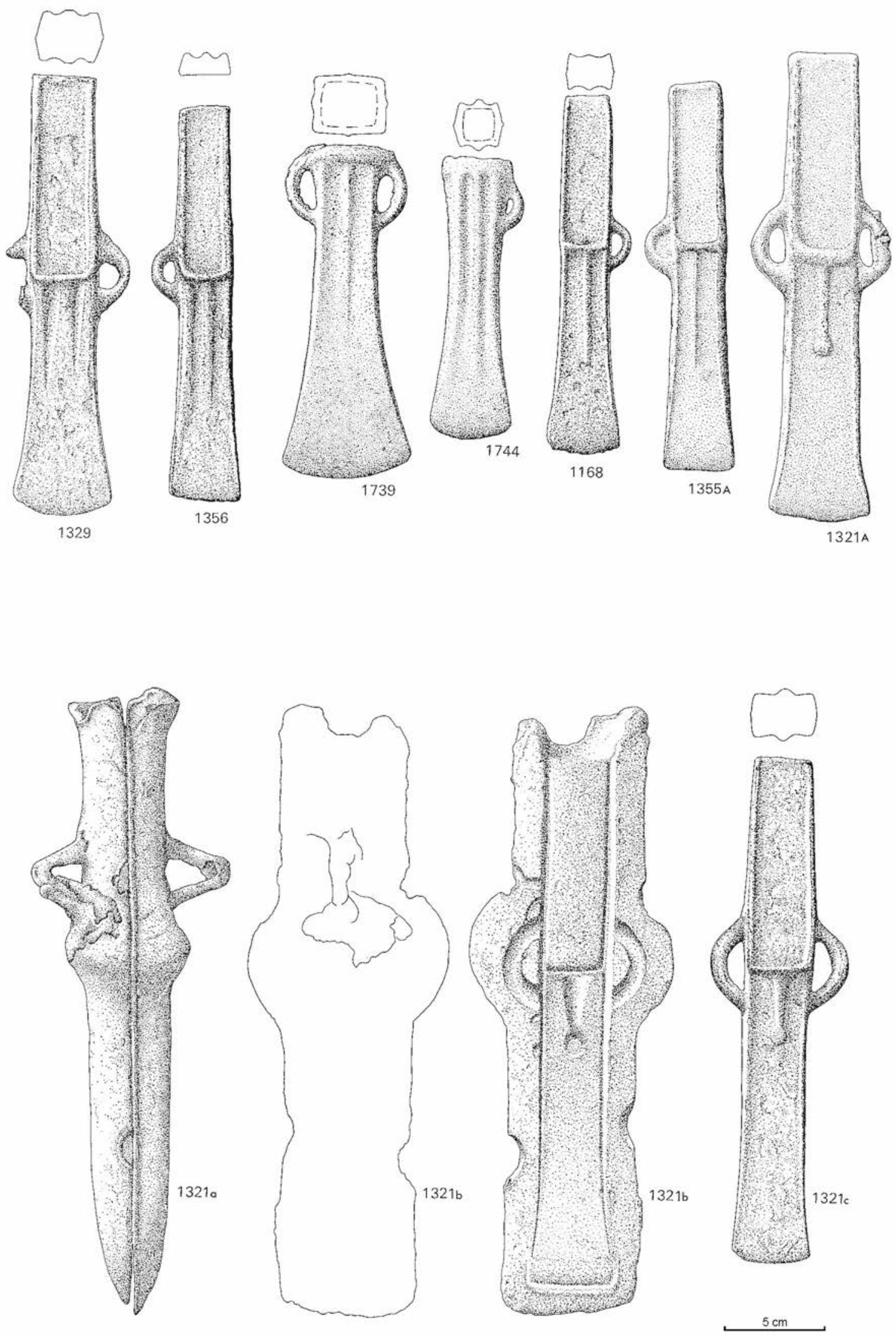

Figura 6. Machados da Retorta (Souselo, Cinfães) $(1329,1356)$, Castro de Mondim da Beira (Mondim, Tarouca) (1168, 1355A, 1321A), Serra do Montemuro $(1739,1744)$ e molde bivalve de Vila Boa (Mões, Castro Daire) (1321a-c) (desenhos de Monteagudo, 1977). 
três peças oferecidas em 1904 por Alberto da Silva Basto ao então Museu Ethnologico Português ${ }^{14}$.

Uma das outras peças corresponde a um segundo machado, também de alvado mas de uma só argola (N. Inventário 10012), que se encontra extraviado, não tendo sido possível identificá-lo no acervo do Museu (Fig. 6, n. ${ }^{\circ}$ 1744) ${ }^{15}$.

Admitimos que a terceira peça, a "lança" inventariada por J. L. de Vasconcelos, corresponda à "lâmina serrilhada" ( ${ }^{\circ}$ Inventário 10359A), igualmente proveniente da serra do Montemuro ${ }^{16}$ (Fig. 9), que tivemos oportunidade de observar.

Sem outras informações, é difícil tecer considerações minimamente seguras sobre estas três peças, não sendo possível, sequer, apontar lugar provável, ou hipotético, de achado. Nada faz crer que sejam provenientes de um único local, admitindo-se como mais provável que aquela última, aliás bastante atípica, corresponda a achado ocorrido em lugar e circunstâncias distintas. Monteagudo refere-se aos dois machados classificando-os como depósito (1977: 251, 253 e Taf. 120), o que é, no caso, admissível.

\subsubsection{Castro de Vila Cova-à-Coelheira (Vila Cova-à-Coelheira, Vila Nova de Paiva)}

Este castro situa-se na margem direita do rio Côvo, afluente do rio Paiva, na freguesia e concelho de Vila Nova de Paiva. As referências bibliográficas ao sítio são antigas (Gama, 1940), embora por vezes se identifique uma ocupação exterior ao reduto fortificado como sendo da Idade do Ferro - fala-se numa "citânia", no sentido de um grande povoado da Idade do Ferro, exterior ao esporão fortificado, mas de facto as ruínas exteriores ao povoado datarão já de época histórica, eventualmente da Idade Média, mas sobretudo de tempos mais recentes (Idade Moderna).

${ }^{14} \mathrm{Na}$ rubrica "Acquisições do Museu Ethnologico Português. Epoca do bronze (e cobre)" diz-se: "O Sr. Alberto Basto offereceu dois instrumentos cortantes e uma lança, provenientes do districto de Viseu" (Vasconcelos, 1904: 308). Trata-se de Alberto da Silva Basto, de Viseu, onde tinha ourivesaria, fundada em 1855 . Os dois machados foram ilustrados pelo então desenhador do Museu, Guilherme Gameiro (1903-1909), prematuramente falecido (13 de Novembro de 1912). João L. Saavedra Machado, o pintor que sucedeu a Guilherme Gameiro naquela função, é o autor da nota necrológica inserta no Arch. Port. (João de Saavedra Machado, "Necrologia. Guilherme Gameiro e o seu labor artístico", Arch. Port., 1. a série, vol. XIX, pp. 188-189); mais tarde evoca, de novo muito elogiosamente, no volume "Alguns Subsídios para uma Iconografia do Prof. Leite de Vasconcelos e do Seu Museu" (Petrus Nonius, vol. VI, Lisboa, 1945, pp. 36-37), o malogrado artista e as suas produções no Museu Ethnologico Português, referenciando alguns exemplos, entre muitos, dizendo: "Entre as peças mais apreciáveis e

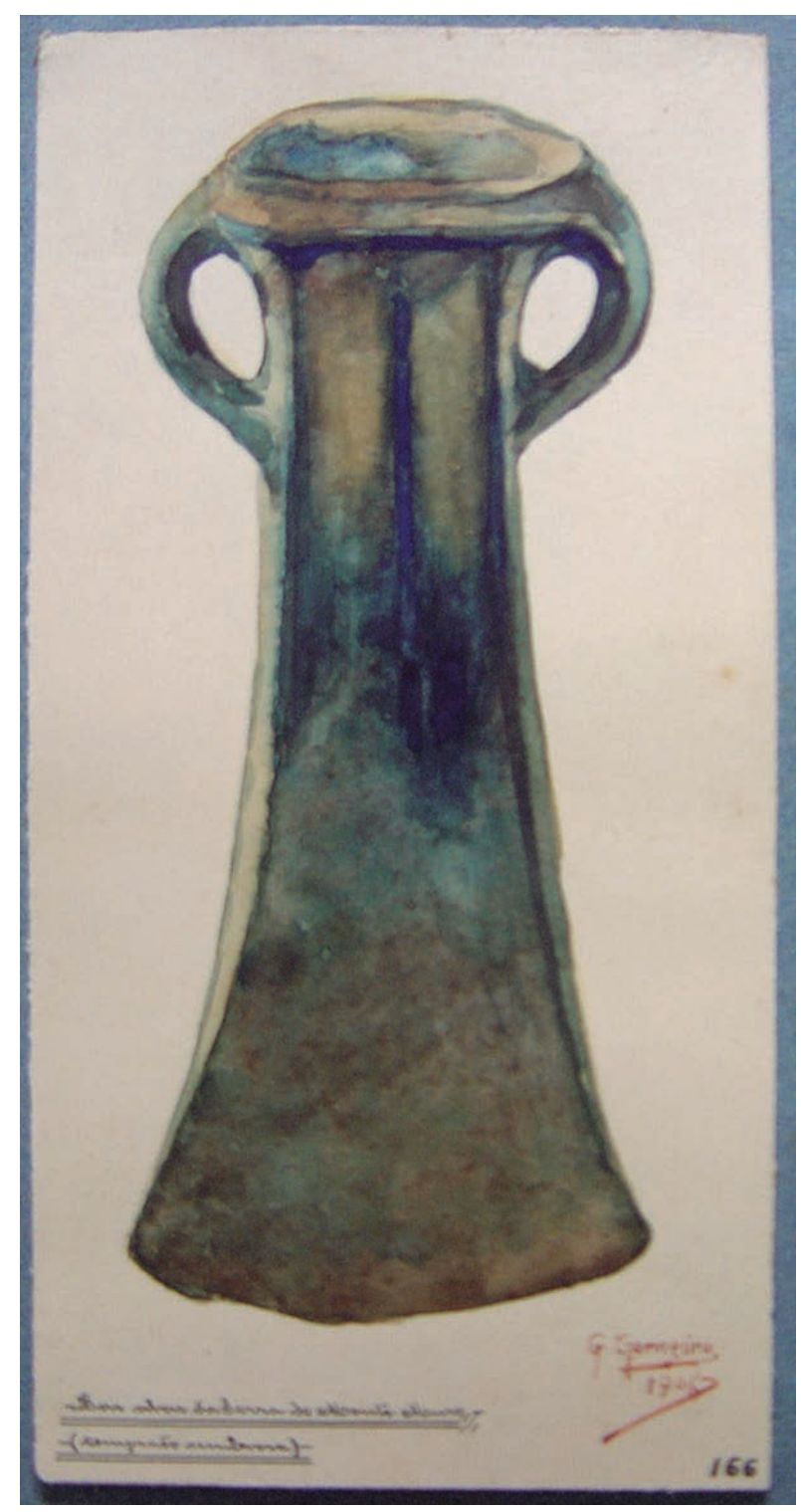

Figura 7. Machado da Serra do Montemuro (desenho de Guilherme Gameiro, 1906).

representativas da iconografia do Museu Etnológico devemos salientar algumas que são devidas aos lápis do saudoso artista Guilherme Gameiro. Que admiráveis não são, por exemplo... [...]. E as reproduções dos machados de bronze das abas da serra do Monte Muro, [...]? [...] [p. 36]. João de Saavedra Machado foi o organizador do $1 .{ }^{\circ}$ álbum de desenho do Museu Etnológico Português, ali integrando obras daquele e outros artistas que trabalharam no Museu (Álbum de Desenho. Arqueologia e Etnografa, MEP, vol. I, Est. 18-166).

15 Agradecemos à Sr. ${ }^{a}$ D. Luísa Guerreiro, técnica do Museu Nacional de Arqueologia, todos os esforços desenvolvidos na pesquisa documental e auxílio na tentativa de localização da peça.

16 Ao contrário dos dois machados, que têm no livro de entradas os números E 3074 a 3076 e onde se diz que entraram em Julho de 1910, a ficha de inventário da lâmina (MNA-10359 A) não refere qualquer data da sua entrada no Museu. 


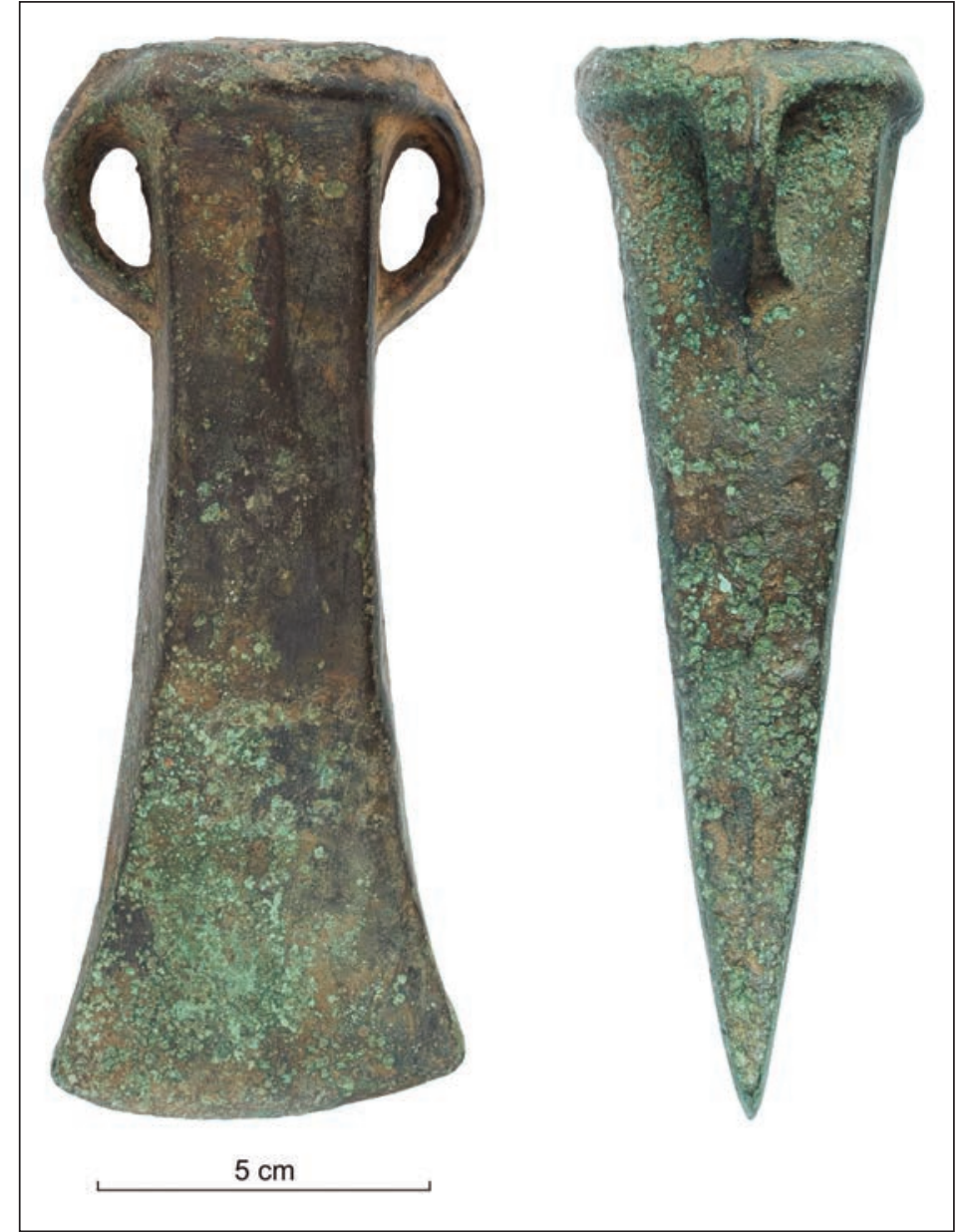

Figura 8. Machado da Serra do Montemuro (fotografia: projecto ALBIMEH).

O sítio foi estudado arqueologicamente em tempo recente por Sílvia Loureiro Mendes e Alexandre Valinho (1998-2002), no âmbito do projecto de investigação "O Alto Paiva - sociedade e estratégias de povoamento desde a Pré-história recente à Alta Idade Média" (coord. de DJC); estes trabalhos deram origem a dissertação de mestrado (2005), entretanto publicada (Mendes, 2009).

O povoado implanta-se em esporão, de topo aplanado, sobranceiro ao curso do rio, oferecendo assim excelentes condições de defesa. A localização é um pouco atípica pois o povoado localiza-se num fundo de vale, algo camuflado pela paisagem mas, de qualquer modo, permitindo o domínio visual, sobretudo para sul, do vale do Côvo (até à junção deste com o Paiva). Os trabalhos de escavação revelaram uma muralha de construção tosca, fortalecida com muros de sustentação interiores e exteriores, nos lados norte e este; esta muralha e o limite dos paredões íngremes do esporão definem um espaço limitado, de planta ovalada (c. 50 m E-O x $30 \mathrm{~m} \mathrm{N-S}$ ); no seu interior, a par dos afloramentos, foram identificadas várias lareiras que se associam a "múltiplas actividades com um carácter doméstico que passam essencialmente pela moagem, prepa- ração, consumo e armazenagem de alimentos e parecem denunciar a existência de estruturas habitacionais, provavelmente cabanas feitas em materiais perecíveis" (Mendes, 2017: 93). A ocupação do sítio terá ocorrido entre meados / finais do séc. IX a. C. e inícios do séc. VIII a. C. (Mendes, 2009: 91). Foi aqui recolhido "numa das lareiras que se insere no momento inicial de ocupação do sítio" (Mendes, 2017: 95) um machado de alvado de duas aselhas (Fig. 10) (Mendes, 2009: 70, fig. 27 , est. XIX), que analisamos neste trabalho.

\subsubsection{Vila Boa (Mões, Castro Daire)}

A povoação de Vila Boa (Mões, Castro Daire) situa-se a su-sudeste da vila de Castro Daire (interflúvio Paiva-Vouga), em plataforma da margem esquerda do rio Paiva. Carlos Teixeira relata o achado nos "arredores de Castro-Daire de um molde de fundição de machados de duplo anel (palstaves), [...] encontrado por um pedreiro, junto dum penedo, nos limites do lugar de Vila-Boa do concelho atrás referido" (Teixeira, 1939: 127, fig. 1 e 2). O molde encontra-se depositado no Museu de História Natural da Faculdade de Ciências da Universidade do Porto (Monteagudo, 1977: Taf. 93: 1321 a-c; Coffyn, 1985: 200) (Figs. 11 e 6, n. 1321 a-c).

\subsection{Os (m)achados do Montemuro e bacia superior do Paiva}

Demos preferência a uma sistematização que visou o enquadramento crono-tipológico. Considerando que, nem sempre mas convencionalmente, existe uma maior antiguidade de fabrico dos machados planos em relação aos de talão e destes em relação aos de alvado, utilizamos uma estratégia de organização baseada neste mesmo critério. Para o final deixamos o molde para machados de talão e a lâmina de gume serrilhado (Figs. 2 e 3).

\subsubsection{Machados planos}

Os três artefactos inseríveis nesta categoria diferem no seu conjunto pela sua tipologia específica, localização e condição de achado.

Proveniente de contexto habitacional, dá-se conta do machado plano de tipo 2 B1, com o gume bastante deformado pelo uso, do Corgo da Maga (Moledo, Castro Daire) (Fig. 3, n. ${ }^{\circ} 1$ e Fig. 4), povoado escavado nos anos 40 do século $\mathrm{XX}$ por Fernando Russell Cortez, como referido, e cuja ocupação terá acontecido durante o Calcolítico e a Idade do Bronze (Cortez, 1951, 1952); o sítio localiza-se já no interflúvio Paiva-Vouga. 


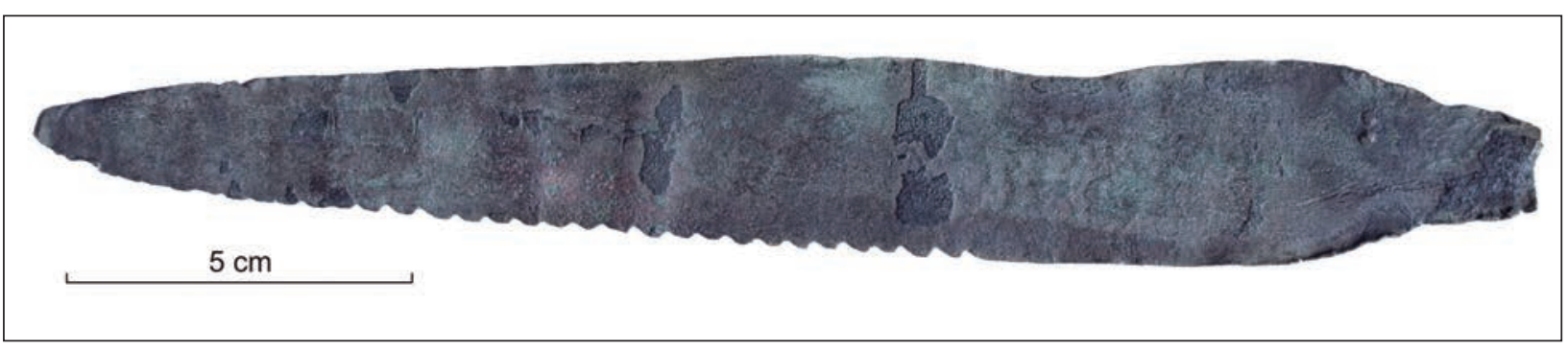

Figura 9. Lâmina com lingueta e gume serrilhado da Serra do Montemuro (fotografia: projecto ALBIMEH).

De contexto desconhecido provém um machado plano de tipo 2 A1 (Fig. 3, n. 2 e Fig. 5, n. ${ }^{\circ}$ 136), atribuído a "Ervilhais"; no aro de Ervilhais é possível associar o artefacto quer ao sítio da Gia (na extremidade nordeste do relevo onde se implanta a pequena ermida da Senhora do Castelo, elevação sobranceira à povoação de Ervilhais), quer ao Dólmen 1 de Chão do Brinco, que dista daquela povoação cerca de $1 \mathrm{~km}$.

O terceiro, proveniente da escavação da Orca de Seixas (Peravelha, Moimenta da Beira), integra-se no tipo 6B (Fig. 3, n. ${ }^{\circ} 3$ e Fig. 5, n. ${ }^{\circ} 427$ ). O seu contexto é de reutilização de um dólmen de corredor construído na primeira metade do IV milénio a. C. (Cruz, 2001: 238) e associava-se a outros materiais de cronologia calcolítica (vasos campaniformes, troncocónicos de fundo plano, braçal de arqueiro, ponta de lança de tipo Palmela, botão em osso com duas perfurações, martelos, etc.) (Leisner, 1998: 15-17, Taf. 2-6, 123b, 124a).

\subsubsection{Machados de talão}

As cinco peças adscritas a esta tipologia provêm dos sítios da Retorta (Souselo, Cinfães) e de Mondim da Beira (Tarouca). Os seus achados contextualizam-se de modo diferente bem como os seus aspectos morfológicos.

Dos cinco machados de talão, três são monofaciais com uma argola e enquadram-se no tipo $36 \mathrm{C}$ e $31 \mathrm{C}$ definido por Monteagudo (1977). O primeiro é um achado avulso, oriundo da Retorta (Vasconcelos, 1913), e os dois restantes encontram-se associados ao povoado fortificado de Mondim da Beira (Tarouca) (Fig. 3, n. ${ }^{\circ}$ 5, 7-8 e Fig. 6, n. ${ }^{\circ}$ 1356, 1168, 1355A).

As restantes duas peças apresentam dupla face, sendo que um dos machados, de dois anéis, de Mondim da Beira, enquadra-se no tipo 35 A (Fig. 3, n. ${ }^{\circ} 6$ e Fig. 6, n. ${ }^{\circ}$ 1321A) tendo também resultado de achado fortuito, tal como o machado atribuído à Retorta, que se enquadra no tipo 35 B (Fig. 3, n. 4 e Fig. 6, n. ${ }^{\circ}$ 1329).

\subsubsection{Machados de alvado}

As três peças que compõem este grupo provêm de igual modo de diferentes contextos.

Como referido, e sem possibilidade de precisar a sua localização, duas peças são atribuídas de modo genérico à Serra de Montemuro. Trata-se de um machado de alvado e dois anéis, integrado no tipo 42 A de Monteagudo, e de um machado de alvado de um anel, do tipo $42 \mathrm{C}$, que não foi possível localizar (Fig. 3, n. ${ }^{\circ}$ 9-10 e Fig. 6, n. $\left.{ }^{\circ} 1739,1744\right)$.

O terceiro machado, de alvado e dois anéis, provém de contexto bem definido e além disso, datado, tendo sido recolhido em escavação do Castro de Vila Cova-à-Coelheira; integra-se no tipo $42 \mathrm{~A}$ (Fig. 3, n. ${ }^{\circ}$ 11 e Fig. 10).

\subsubsection{Molde para machados de talão}

Representativo da actividade metalúrgica, contamos com o achado avulso de um molde em bronze para a produção de machados de talão de duas argolas (Fig. 3, n. ${ }^{\circ}$ 12; Fig. 6, n. ${ }^{\circ} 1321$ a-c; e Fig. 11). Enquadra-se no tipo 35 A de Monteagudo e provém do aro da povoação de Vila Boa (Castro Daire). A nível tecnológico, foi alvo de especial atenção por parte de Barbara Armbruster, que identificou na face exterior de uma das valvas e numa das argolas, vestígios de reparação (Armbruster, 2000: 42, Taf. 102 e 103). Posteriormente, mereceu leitura de um outro prisma, que o valorizou em termos simbólicos e metafóricos (Vilaça, 2007: 86) e, mais recentemente, foi integrado em estudo monográfico sobre os exemplares peninsulares de moldes de bronze para machados (García-Vuelta et al., 2014).

\section{Contributos da Arqueometalurgia}

Entre os 13 artefactos metálicos atribuídos ao território em estudo, apenas 4 dispõem de análises arqueométricas; dois machados de alvado de duas argolas [n. ${ }^{\circ}$ 9 e 11], o machado plano de Ervilhais [n. ${ }^{\circ}$ 2] e a lâmina de gume serrilhado do Montemuro [n. $\left.{ }^{\circ} 13\right]$. Deve ser sublinhado que essas análises resultam de projectos de distintas equipas, as quais utilizaram equipamentos e protocolos analíticos igualmente diferenciados.

Referindo-nos ao primeiro machado, proveniente do Montemuro, foi analisado no âmbito do projecto ALBIMEH (Armada e Martinón-Torres 2016), por Fluorescência de raios-X por energias dispersivas com espectrómetro portátil Innov-X System de Olympus, com ânodo de ródio como fonte de raios-X e equipado com Silicon Drif Detector (SDD), empregando um 


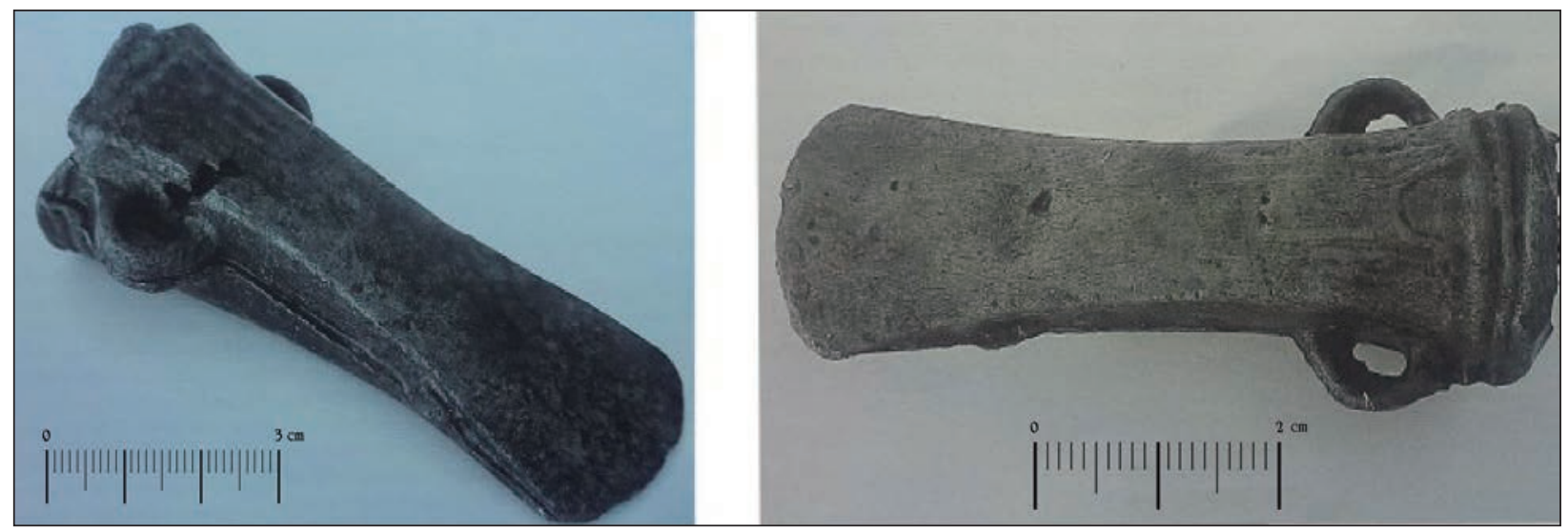

Figura 10. Machado do Castro de Vila Cova-à-Coelheira (Vila Cova-à-Coelheira, Vila Nova de Paiva) (fotografias adaptadas de Mendes, 2009).

protocolo baseado no programa Alloys de Innov- $X$ e optimizado no UCL Institute of Archaeology para a análise de ligas arqueológicas. Este programa funciona com voltagem de aceleração de $40 \mathrm{kV}$, corrente de 100 $\mu \mathrm{A}$, filtro de alumínio de $2 \mathrm{~mm}$ de espessura e colimador de $3 \mathrm{~mm}$ de diâmetro. $\mathrm{O}$ tempo de aquisição foi de 40 segundos por medição. Os espectros quantificaram-se mediante o software Alloys criado por Innov- $X$ Systems, baseado numa combinação de parâmetros fundamentais e estandardização com padrões de referência, que oferece os resultados normalizados a $100 \%$ em peso. A análise realizou-se numa das partes laterais do machado, após prévia remoção da pátina; os valores quantitativos que disponibilizamos correspondem a uma média de três medidas analíticas com valores praticamente idênticos. Ademais, realizou-se uma análise sobre a pátina na zona do gume.

Também o segundo machado de alvado [n. $\left.{ }^{\circ} 11\right]$, exumado no Castro de Vila Cova-à-Coelheira, foi analisado por Fluorescência de raio-X, mas no Instituto de Soldadura e Qualidade (Mendes, 2009: 70).

Já as duas outras peças - o machado plano de Ervilhais [n. ${ }^{\circ}$ 2] e a lâmina serrilhada do Montemuro [n. $\left.{ }^{\circ} 13\right]$ - foram analisadas através de espectrometria de emissão, na sequência do famoso estudo conduzido por Junghans, Sangmeister e Schröder (1968: 26-27, 30-31).

Como se confirma na Figura 12, as diferenças composicionais são várias, nomeadamente quando comparamos a constituição ternária do machado do Castro de Vila Cova-à-Coelheira com a peça de idêntica tipologia do Montemuro, de composição binária, e estas com as produções totalmente em cobre do machado plano de Ervilhais e da lâmina proveniente do Montemuro, esta última com valores de arsénico mais elevados. No caso do machado do Castro de Vila Cova-à-Coelheira, a monografia de Mendes (2009: 70) reporta unicamente os valores de três elementos $(\mathrm{Cu}, \mathrm{Sn}$ e $\mathrm{Pb})$, que não aparecem normalizados a $100 \%$. Tão pouco se especifica se a análise foi realizada com ou sem pátina. Em todo caso, não há dúvida de que se trata de um bronze ternário.

Demonstrativos não só de alterações tecnológicas, estes dados são também indicativos de diferenças cronológicas no que respeita à inovação do processo metalúrgico por parte das comunidades que habitaram estas áreas serranas. Considerando o conjunto do Montemuro e a ausência de análises para todos os elementos, apontamos alguns achados alvo de estudos analíticos de modo a poder detectar padrões composicionais e estabelecer comparações tipológicas e crono-culturais entre regiões.

Proveniente de Mesão Frio, dá-se conta de um machado plano (Monteagudo, 1977: 56), tipologicamente comparável ao machado de Ervilhais (Cinfães) e ao do povoado do Outeiro da Maga. A sua caracterização química, efectuada por Junghans e colegas (1968: 28-29, n. ${ }^{\circ}$ 1559), aproxima-se muito à do machado plano de Ervilhais. Apresenta igualmente percentagens elevadas de cobre $(99,13 \%)$ e residualmente de arsénico $(0,78 \%)$ e níquel $(0,09 \%)$. Mais para sul, em Germil, Penalva do Castelo, a análise a um machado semelhante revela valores de uma total composição em cobre (Junghans et al., 1968: 38-39; Monteagudo, 1977: 52, Taf. $14 \mathrm{n}^{\mathrm{o}}$ 265; Monteagudo, 1965: 22, Lam. 1, n. ${ }^{\circ}$ 3). Ao concelho de Castelo de Paiva, de acordo com o publicado (Junghans et al., 1968: 32-33), atribui-se um machado plano e uma faca cujas análises químicas revelam, respectivamente, percentagens de cobre a 96,49\% e 97,09\%. Ambos apresentam $3,45 \%$ e $2,85 \%$ de arsénico, sendo que apenas a faca revelou um teor muito baixo de $\mathrm{Sn}-0,066 \%$.

No que se refere aos machados de talão, apesar de no conjunto de materiais do Montemuro não existir nenhum elemento para comparação, importa relevar, por questões geográficas, os valores atribuídos a 10 exemplares com duas argolas de Nossa Senhora da Guia de Baiões. Com variações na percentagem de cobre entre os $61,8 \%$ e os $81,2 \%$ e de estanho entre os $18 \%$ e os $44 \%$, os restantes elementos como o chum- 


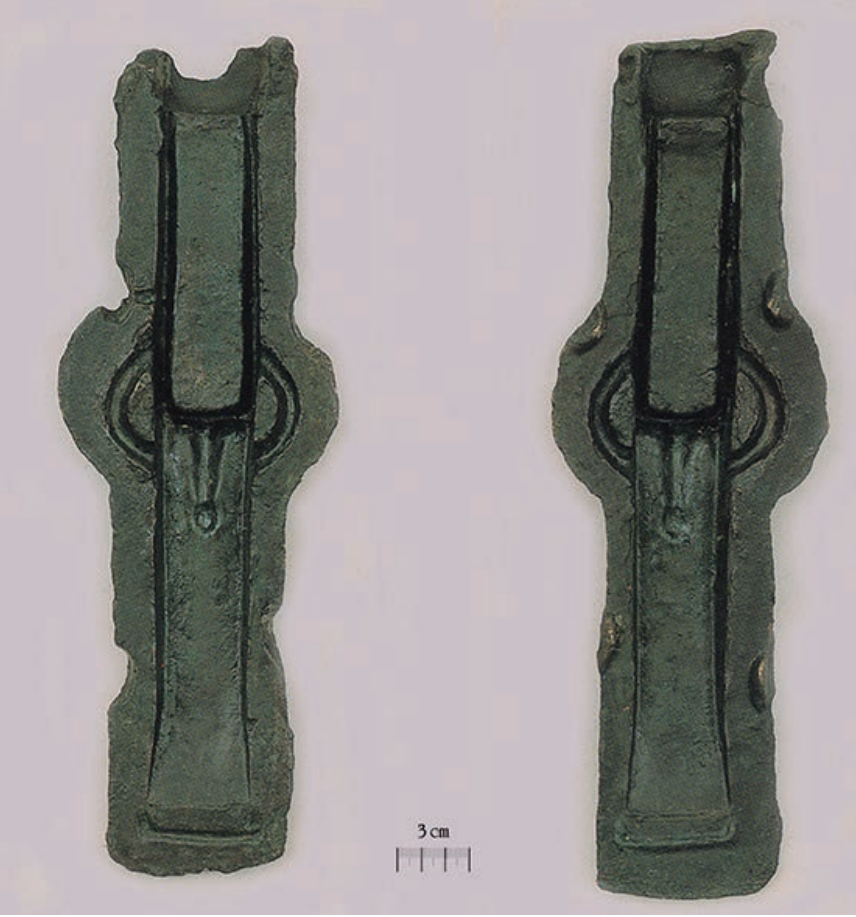

Figura 11. Molde para machados de Vila Boa (Mões, Castro Daire) (fotografia: Barbara Armbruster, adap.).

bo, antimónio, arsénico ou ferro, apresentam percentagens muito baixas, comuns de elementos traço e não de adições propositadas (Valério et al., 2006: 301-302) ${ }^{17}$. Também o depósito de Vila Cova de Perrinho, Vale de Cambra, conta com dois machados de talão, de uma argola e de duas, igualmente com composição binária (Bottaini, 2012: 122-123). A norte, os 9 machados de talão com duas argolas de Viatodos (Barcelos) apresentam composição binária à excepção de um, ternário. Também o depósito da Solveira (Montalegre) contém produções binárias ainda que o machado de talão de duas argolas do conjunto se apresente ligeiramente chumbado.

Os machados de talão unifaciais de uma argola provenientes da Retorta [n. ${ }^{\circ}$ 5] e do Castro de Mondim da Beira [n. ${ }^{\circ}$ 6-7] encontram paralelo tipológico em vários pontos da Península Ibérica. Por exemplo, os depósitos de Coles de Samuel (Soure), Maria Candal
(Freixianda) ou Porto do Concelho (Mação), apresentam objectos desta tipologia relacionáveis com produções binárias (Bottaini, 2012: 136; 159; 180; Bottaini et al., 2016; Bottaini et al., 2017; Vilaça et al., 2012). Lamentavelmente não dispomos de dados geograficamente mais próximos à realidade em estudo.

Relativamente aos dois machados de alvado do Montemuro, contamos, como referido, com os resultados analíticos de dois. $\mathrm{O}$ exame ao primeiro machado [n. ${ }^{\circ}$ 9] revelou uma produção binária com percentagens de estanho ligeiramente elevadas $(16,54 \%)$ com paralelos em objectos do mesmo tipo do centro do território português, nomeadamente em um dos exemplares do depósito do Cabeço de Maria Candal (Ourém), com 16,11\% (Vilaça et al., 2012). Por outro lado, o resultado da análise de fluorescência de raios- $X$ efectuado ao machado de Castro de Vila Cova-à-Coelheira [n. $\left.{ }^{\circ} 11\right]$ revelou composição ternária (Cu: 59,82\%; Sn: 25,04\%; Pb: 12,44\%) (Mendes, 2009: 70), aproximando-se do grupo mais setentrional e com paralelos, por exemplo, nas peças do Castro de Fiães (Bottaini, 2012: 251-252), de Santo Tirso (Melo e Araújo, 2000: 56) ou no da Ribeira, rio Cávado, em Braga (Bettencourt, 2001: 31-33).

\section{DiscuSSÃo E INTEGRAÇÃO CRONO-CULTURAL}

De acordo com os artefactos metálicos que compõem o acervo proveniente do território montemurano e seus arredores, podemos afirmar que estamos perante testemunhos de produção metalúrgica em épocas recuadas, nomeadamente desde o Calcolítico. A crer nas morfologias e tecnologia desta época, estes têm particular expressão quando avaliamos as composições cupríferas do machado de Ervilhais e da lâmina serrilhada atribuída ao Montemuro. O machado plano do Outeiro (ou Corgo) da Maga [n..$^{\circ}$ 1], ainda não analisado, e supostamente em associação a fundo de cabana "dos primórdios do eneolítico" (Cortez, 1952: 228), enquadra-se genericamente, pela tipologia, no mesmo período. No mesmo sentido aponta o machado plano

\begin{tabular}{|c|c|c|c|c|c|c|c|c|c|c|c|c|c|}
\hline $\mathbf{N}^{\circ}$ & Localização & Observ. & $\mathbf{F e}$ & $\mathbf{N i}$ & $\mathrm{Cu}$ & $\mathbf{Z n}$ & As & Ag & Sn & Sb & $\mathbf{A u}$ & $\mathbf{P b}$ & $\mathbf{B i}$ \\
\hline 2 & Ervilhais & & -- & -- & 99,58 & -- & 0,42 & -- & -- & -- & -- & -- & -- \\
\hline \multirow{2}{*}{9} & \multirow{2}{*}{ Montemuro } & & nd & nd & 83,03 & 0,05 & 0,14 & nd & 16,54 & 0,12 & nd & 0,12 & nd \\
\hline & & Pátina & 0,42 & nd & 54,44 & nd & 0,88 & 0,23 & 43,4 & 0,27 & 0,05 & 0,31 & nd \\
\hline 11 & V. C. Coelheira & & -- & -- & 59,82 & -- & -- & -- & 25,04 & -- & -- & 12,44 & -- \\
\hline 13 & Montemuro & & -- & 0,025 & 95,77 & -- & 4,2 & $\mathrm{Tr}$ & -- & -- & -- & & 0,01 \\
\hline
\end{tabular}

Figura 12. Resultado das análises químicas às peças da região do Montemuro.

17 As análises realizaram-se sem remoção de pátina, mas é inequívoco o carácter binário nas ligas empregadas. Um dos machados apresenta 54,6\% de $\mathrm{Cu}$, mas os restantes nove situam-se na categoria referida. Um dos machados analisados é unifacial, enquanto os nove restantes são bifaciais. 
[n. 3] da última fase de utilização da Orca de Seixas (Moimenta da Beira), encontrado em associação com uma ponta de tipo Palmela, um braçal de arqueiro e cerâmica campaniforme (Leisner, 1998: 15-17).

Na região em análise, e face aos dados existentes, não é possível desenvolver grandes considerações sobre o sentido evolutivo da produção metalúrgica. Dos mais simples machados planos, em cobre, passa-se às produções em bronze de ligas binárias e ternárias. Tratam-se de machados de talão ou de alvado em que os primeiros têm sido apresentados como expressão máxima dos contactos entre o mundo atlântico e peninsular durante o final da Idade do Bronze (Coffyn, 1985: 219).

Não obstante, a presença de machados de talão unifaciais com uma argola pode indiciar, de acordo com alguns autores, uma maior antiguidade destes em relação às peças bifaciais, de uma ou duas argolas ${ }^{18}$. Considerando correcta a contextualização estratigráfica de um objecto desta tipologia, de constituição binária, proveniente do primeiro momento de ocupação do Castro do Cabeço de S. Romão (Seia), com datações de radiocarbono que o colocam entre os séculos XIV-X a. C., poder-se-á, de facto, recuar este tipo de produções a uma fase mais inicial do Bronze Final, pelo menos ao último quartel do II milénio a. C. (Gil et al., 1989: 239; Senna-Martinez, 1995: 118-120; Bottaini, 2012: 416). Todavia, a realidade parece demonstrar que a produção, circulação e deposição deste tipo de machados se regista em conjuntos de época posterior.

Tomemos como exemplo o Castro da Senhora da Guia de Baiões, local de depósito de diversos materiais metálicos atribuídos a fases mais tardias do Bronze, entre os quais se encontra um molde em bronze para produção de machados de talão unifaciais de uma argola. Este registo é ainda de particular interesse porque demonstrativo da produção deste tipo de machados no Centro do território português, região tida como genuína zona do seu fabrico (Coffyn, 1985: 267).

A julgar pelos vários conjuntos deposicionais de território português, Vila Cova de Perrinho, Coles de Samuel, Cabeço de Maria Candal ou Porto do Concelho, compostos por várias tipologias de machados de talão, poderemos atribuir uma ampla cronologia de produção e consumo destes materiais durante o primeiro quartel do I milénio a. C. (Bottaini, 2012: 139; Vilaça et al., 2012: 343).

Vale ainda a pena sublinhar que, de um ponto de vista regional, o Montemuro e área circundante ofere-

18 Contra esta ideia seria de referir os primeiros exemplares de machados de talão sem anéis, anteriores na sequência tipológica e de carácter bifacial (Suárez Otero, 2000; Delibes et al., 2016). cem uma peculiar situação respeitante à produção e circulação dos distintos tipos de machados de talão. Trata-se do único caso da Península Ibérica, concretamente da sua fachada atlântica, em que, relativamente perto (numa distância de uns $20 \mathrm{~km}$ em linha recta) ${ }^{19}$ foram encontrados dois moldes de bronze, um de machados de talão e de duas argolas (Vila Boa), outro de machados unifaciais de uma argola (Baiões), neste caso associado ao respectivo machado, demonstrativo da sua produção local. Trata-se igualmente de uma região em que circulam machados de ambos os tipos.

Se não é possível relacionar directamente os machados unifaciais da Retorta e de Mondim da Beira com o molde de Baiões, nem, do mesmo modo, os nove machados de talão e duplo anel de Baiões, ou os de idêntico tipo da Retorta e de Mondim da Beira, com o molde de Vila Boa, a verdade é que, uns e outros, configuram um território bastante expressivo, e singular, da produção e circulação destas duas categorias de artefactos.

Quanto aos dois machados de alvado identificados na região da serra do Montemuro apresentam diferenças tipológicas. O machado de uma argola ostenta três nervuras que, segundo Hardaker (1976: 158), são uma característica particular da Península Ibérica. Já os mais expressivos à escala peninsular, segundo o mesmo autor, são os machados de alvado de duas argolas, que no conjunto em apreço possuem face plana [n. ${ }^{\circ}$ 9] ou decorada com vários sulcos [n. $\left.{ }^{\circ} 11\right]$. Como é sabido, são objectos cuja distribuição tem maior expressão no Noroeste peninsular e Estremadura portuguesa, com produção que terá ocorrido durante os séculos IX-VIII a. C. (Hardaker, 1976: 159-160, 164-165; Coffyn, 1985: 219-221). Actualmente existem dados cronológicos de radiocarbono que permitem confirmar a correcta atribuição desta cronologia, comprovada pela datação do contexto do machado de Vila Cova-à-Coelheira, entre os séculos IX e VIII a. C. (Mendes, 2009: 70; 88-90).

Sobre este tipo de machados, Bottaini (2012: 433) define dois modelos quanto à sua caracterização composicional. Um, é caracterizado por ligas binárias e corresponde aos exemplares do Centro de Portugal. O outro, com composições ternárias, concentra-se a norte do rio Vouga. Como visto, o machado do Castro de Vila Cova [n. $\left.{ }^{\circ} 11\right]$ parece respeitar a regra das produções ternárias, concentradas a norte enquanto que o machado que estudámos [n. ${ }^{\circ}$ 9], embora localizado a norte do Vouga, integra-se, pela sua composição binária, no grupo do Centro de Portugal. A interpretação destes dados, associada ao facto de também um

19 Os exemplares de Friol (Lugo, Galiza) e Oscos (Astúrias) são mais distantes entre si (García-Vuelta et al., 2014: 132-135). 
machado de alvado de Candemil (Amarante) apresentar uma produção binária (Bottaini, 2012: 250-251), revela que aqueles dois modelos devem ser entendidos de forma aberta e não de modo rígido, como aliás o autor muito bem sublinhou. O limite do Vouga deve ser visto, por conseguinte, como orientador e não linear, não surpreendendo a existência dos dois tipos de ligas numa área de "fronteira" e de passagem, como é o caso presente.

A completa, ou até mesmo aproximada, contextualização de cada um dos objectos da região nem sempre foi possível, principalmente no que respeita aos elementos atribuídos, de forma genérica, ao Montemuro. Também aos elementos provenientes do concelho de Cinfães e ao molde de Vila Boa (Castro Daire) associam-se contextos pouco claros, desconhecendo-se a sua deposição ou associação a pontos ou mancha de povoamento explícitos.

Os machados de talão da Retorta (Souselo) não permitem, por enquanto, a sua integração ou conexão a qualquer sítio habitacional da zona, admitindo-se como muito provável corresponderem a depósito duplo; é igualmente insegura a origem do machado plano de Ervilhais, que pode relacionar-se, como referido, com o lugar de Gia / Castelo (ou Nossa Senhora do Castelo), elevação sobranceira àquela povoação e à qual se associa uma via medieval, talvez decalcando caminhos ou rotas milenares, mas também às reutilizações tardias do Dólmen 1 de Chão do Brinco, que se localiza próximo daquela aldeia.

Sobre o molde de bronze para machados de talão de Vila Boa, apenas se sabe que a sua descoberta foi efectuada "perto de um penedo" (Teixeira, 1939: 127), importando, num futuro próximo, desenvolver prospecções na área com vista à sua valorização em termos de arqueologia espacial. A peça é de capital importância, como ficou já frisado, oferecendo contexto de achado similar ao molde de La Macolla (Linares de Riofrío, Salamanca) (García-Vuelta et al., 2014).

À partida, poder-se-á afirmar que a utilização de peças em cobre e ligas de cobre no território sob influência montemurana acontece desde o Calcolítico. Por outro lado, importa realçar que certos tipos metálicos poderão ter perdurado no tempo e que o achado de peças consideradas mais antigas, concretamente alguns machados planos, de assinalável variabilidade formal, poderá ser reflexo da manutenção de determinada tipologia / tecnologia, por questões funcionais ou outras. Recorde-se, a propósito, o importante molde de machados planos de Casarão da Mesquita 3 (S. Manços, Évora), de contexto do Bronze Final (Soares et al., 2007).

Sublinhe-se também que a valorização da tecnologia e das composições químicas dos objectos enquanto elementos demarcadores cronológicos deve ser encarado com igual cuidado. Tal como se conhecem peças totalmente produzidas em cobre ainda no fim da Idade do Bronze, também o tipo de produções metalúrgicas com ligas ternárias, tradicionalmente integradas já na Idade do Ferro (Bettencourt, 2001: 31; Montero-Ruiz et al., 2003), não deve ser tido como garantido, mas sim como elemento norteador entre as duas fases cronológicas.

Sem uma mais profunda análise a todos os dados não nos será possível extrair informação mais precisa, no entanto, baseados nos dados que temos, poderemos assumir que a relação das comunidades desta região com os artefactos metálicos não seria meramente de utilização / consumo, mas sim de produção, a julgar pelo molde de Vila Boa, seguindo o modelo proposto por vários autores (v.g. Coffyn, 1985; Silva, 2007), que consideram o Centro e Norte de Portugal como centros produtores deste tipo de objectos. Será necessário escavar contextos habitacionais para conhecer os meios e instrumentos de produção do ciclo produtivo do trabalho do metalurgista. A associação desta região a várias jazidas de estanho, e a sua posição de dupla interface entre o Noroeste, o litoral Beirão e a Beira Interior, poderão também ser factor essencial aos contactos com outras comunidades, potencializando as relações desta com outras áreas periféricas. Por outro lado, face à inexistência de recursos cupríferos na região de Montemuro, não poderá ser ignorado o potencial mineiro pré-histórico da Cordilheira Cantábrica (Blas Cortina e Suárez Fernández, 2010) e os possíveis ou eventuais fluxos de metal dessa região para o Atlântico ocidental, nomeadamente o Norte e Centro de Portugal (v.g. Coffyn, 1985: 228, 267; Ruiz-Gálvez Priego, 1986: 27-28; Blas Cortina, 1991-92: 133).

Os exemplares recolhidos, embora sem a localização precisa de alguns, evidenciam a importância da actividade metalúrgica e das comunidades que viveram e circularam na serra do Montemuro e seu aro a partir do Calcolítico e no decurso da Idade do Bronze, concretamente nos seus finais. A elaboração de uma carta de distribuição de tais vestígios, que permite integrá-los em termos geo-morfológicos, terá também de ser valorizada com a concretização de futuro trabalho de campo orientado para problemáticas específicas que uma das autoras (DF) pretende desenvolver. Importa, evidentemente, associá-los a outros registos coevos, como o do povoado de São Lourenço (Mões, Castro Daire), onde a recente identificação de cerâmica incisa pós-cozedura de tipo Baiões permite admitir ocupação mais remota do que se julgava (Dias, 2017: 821), e importa valorizá-los na sua conexão com o espaço.

Perante o quase total desconhecimento existente sobre o quotidiano dessas comunidades, encaram-se estes dados, muito parcelares, como um esforço à prossecução de novos estudos. Urge a caracterização dos sistemas social, económico e cultural das populações desta área de fronteira entre o Norte e o Centro do território português. 


\section{Agradecimentos}

Este artigo faz parte dos projectos de investigação "Atlantic Late Bronze Age interaction through metal hoards" (Project $n^{\circ}$ 628959) (IEF Marie Curie) e "Innovación tecnolóxica, circulación do metal e artefactos metálicos de prestixio na Europa atlántica (s. XIII-I ANE)" (IN607D 2016/004) (Proxectos de Excelencia, Xunta de Galicia). Agradecemos a Anxo R. Paz, a Ana Pernas e a José Luís Madeira a sua colaboração na parte gráfica do artigo. E ainda ao(s) revisor(es) anónimo(s), cuja leitura e sugestões contribuíram para melhorar o texto.

\section{Bibliografia}

Armada, X.-L. (2015): “Sacrificio, consumo cárnico y religión del Bronce Atlántico a los celtas occidentales", in F. J. García Fernández, F. Lozano Gómez e A. Pereira Delgado (eds.), El alimento de los dioses. Sacrificio y consumo de alimentos en las religiones antiguas. Spal Monografías, XX. Editorial Universidad de Sevilla. Sevilla: 123-156.

Armada, X.-L., Martinón-Torres, M. (2016): “The ALBIMEH project - Atlantic Late Bronze Age metal hoards compared". Archaeology International, 19: 49-53. http://doi.org/10.5334/ai.1908

Armbruster, B. R. (2000): Goldschmiedekunst und Bronzetechnik. Studien zum Metallhandwerk der Atlantischen Bronzezeit auf der Iberischen Halbinsel. Monographies Instrumentum, 15. Montagnac.

Armbruster, B. R. (2010): "Lithic technology for Bronze Age metal working", in B. V. Eriksen (ed.), Lithic technology in metal using societies. Proceedings of a UISPP Workshop, Lisbon. Jutland Archaeological Society Publications, 67. Aarhus: 9-22.

Bettencourt, A. M. S. (2001): “Aspectos da metalurgia do bronze durante a proto-história do entre Douro e Minho". Arqueologia, 26: 13-40.

Blas Cortina, M. A. (1991-92): "Nuevos testimonios metalúrgicos de la Edad del Bronce en el CentroOccidente de la región cantábrica". Veleia, 8-9: 109-137.

Blas Cortina, M. A., Suárez Fernández, M. (2010): “La minería subterránea del cobre en Asturias: un capítulo esencial en la Prehistoria reciente del norte de España", in J. A. Fernández-Tresguerres (coord.), Cobre y oro. Minería y metalurgia en las Asturias prehistórica y antigua. Oviedo: 43-82.

Bottaini, C. (2012): Depósitos metálicos no Bronze Final (sécs. XIII-VII A.C.) do Centro e Norte de Portugal. Aspectos sociais e arqueometalúrgicos. Universidade de Coimbra [Dissertação de Doutoramento].
Bottaini, C., Vilaça, R., Montero-Ruiz, I., Mirão, J., Candeias, A. (2017): "Archaeometric contribution to the interpretation of the Late Bronze Age 'hoard' from Porto do Concelho (Mação, Central Portugal)". Mediterranean Archaeology and Archaeometry, 17 (1): 217-231. http://doi.org/ 10.5281/zenodo.400779

Bottaini, C., Vilaça, R., Schiavon, N., Mirão, J., Candeias, A., Bordalo, R., Paternoster, G., Montero-Ruiz, I. (2016): "New insights on Late Bronze Age $\mathrm{Cu}$-metallurgy from the Coles de Samuel hoard (Central Portugal): A combined multi-analytical approach". Journal of Archaeological Science: Reports, 7: 344-357. http://dx.doi.org/10.1016/j.jasrep.2016.05.009

Canha, A. J. (2002): Canedotes: povoado do Bronze Final do Alto Paiva. Faculdade de Letras, Universidade do Porto [Dissertação de Mestrado em Arqueologia].

Capela, J. V., Matos, H. (2010): As Freguesias do Distrito de Viseu nas Memórias Paroquiais de 1758. Memórias, História e Património. Braga.

Carreira, J. R. (1994): “A Pré-História Recente do Abrigo Grande das Bocas (Rio Maior)". Trabalhos de Arqueologia da EAM, 2: 47-144.

Coffyn, A. (1985): Le Bronze Final Atlantique dans la Péninsule Ibérique. Paris.

Correia, A., Alves, A., Vaz, J. L. I. (1995): Castro Daire, $2^{\mathrm{a}}$ ed. Castro Daire [1. ${ }^{\mathrm{a}}$ ed.: 1986].

Cortez, F. R. (1951): “Das populações pré-celtas do Norte de Portugal". Boletim da Associação da Filosofia Natural, II, 21: 159-184.

Cortez, F. R. (1952): "Contributo para o estudo do Neolítico de Portugal". Trabalhos de Antropologia e Etnologia, XIII (3-4): 193-248.

Cruz, D. J. (1998): "Expressões funerárias e cultuais no Norte da Beira Alta (V - II milénios a. C.)", in Actas do Colóquio "A Pré-história na Beira Interior" (Tondela, Nov. 1997). Estudos Pré-históricos, 6. Viseu: 149-166.

Cruz, D. J. (coord.) (2000): Roteiro Arqueológico de Vila Nova de Paiva. Vila Nova de Paiva.

Cruz, D. J. (2001): O Alto Paiva: megalitismo, diversidade tumular e práticas rituais durante a Pré-história Recente, Universidade de Coimbra [Dissertação de Doutoramento].

Cruz, D. J., Santos, A. T. (2011): “As estátuas-menires da serra da Nave (Moimenta da Beira, Viseu) no contexto da ocupação pré-histórica do Alto Paiva e da Beira Alta", in R. Vilaça (ed.), Estelas e Estátuas-menires: da Pré- à Proto-história. Actas das IV Jornadas Raianas (Sabugal, 2009). Sabugal: 117-142. 
Delibes de Castro, G., Fernández Manzano, J., Herrán Martínez, J. I. (2016): “Tipología y composición de las hachas de talón ibéricas", in E. Galán, O. García Vuelta e I. Montero-Ruiz (eds.), Hachas de talón del Museo Arqueológico Nacional. Catálogo y estudio arqueometalúrgico. Madrid: 87-133.

Dias, J. (1951): "Les troupeaux transhumants et leurs chemins", in Comptes rendus du Congrès International de Géographie (Lisbonne, 1949) (t. III). Lisboa: 23-32.

Dias, J. (1965): “Aspectos da vida pastoril em Portugal". Revista de Etnografia, IV (2): 346-370.

Dias, V. (2017): "Povoado de São Lourenço. Novos dados. Castro Daire, Viseu (CNS 5114)", in Arqueologia em Portugal 2017 - Estado da Questão. Lisboa: 819-823.

Díaz-Andreu, M. (1988): “El análisis discriminante en la clasificación tipológica: aplicación a las hachas de talón de la Península Ibérica". Boletín del Seminario de Estudios de Arte y Arqueología, 54: 25-64.

Ferreira, A. B. (1978): Planaltos e Montanhas do Norte da Beira. Estudo de Geomorfologia. Memórias do Centro de Estudos Geográficos, 4. Lisboa.

Ferreira, A. B. (2004): "O Norte da Beira”, in M. Feio e S. Daveau (coords.), O Relevo de Portugal. Grandes Unidades Regionais. Publicações da Associação Portuguesa de Geomorfólogos, vol. II. Coimbra: 97-110.

Gama, M. F. (1940): Terras do Alto Paiva. Memória Histórico-geográfica e Etnográfica do Concelho de Vila Nova do Paiva. Lamego.

Gameiro, R. G. (1906): Álbum de Desenho. Arqueologia e Etnografia, vol. I. Lisboa.

García-Vuelta, O., Cuesta-Gómez, F., Galán Domingo, E., Montero-Ruiz, I. (2014): "Los moldes de fundición de bronce para hachas de talón de La Macolla (Linares de Riofrío, Salamanca). Nuevos datos sobre viejos hallazgos". Zephyrus, LXXIV: 117-141. http://dx.doi.org/10.14201/zephyrus201474117141

Gil, F. B., Senna-Martinez, J. C., Guerra, M. F., Seruya, A. I., Fabião, C. (1989): "Produções metalúrgicas do Bronze Final do Cabeço do Crasto de S. Romão, Seia: uma primeira análise", in Actas do I Colóquio Arqueológico de Viseu. Viseu: 235-248.

Girão, A. A. (1921): Antiguidades Pre-históricas de Lafões. Contribuição para o Estudo da Arqueologia de Portugal. Coimbra.

Girão, A. A. (1940): Montemuro. A mais desconhecida serra de Portugal. Coimbra.

Girão, A. A. (1951): Geografia de Portugal. (Acrescida do Estudo das Ilhas Adjacentes), 2. ${ }^{\mathrm{a}}$ ed. Porto [1. ed. 1949].

Guimarães, J. G. O. (1900): "Inscripções inéditas". Revista de Guimarães, 17 (4): 183-186.
Hardaker, R. (1976): "Las hachas de cubo en la Península Ibérica". Cuadernos de Prehistoria y Arqueología Castellonense, 3: 151-171.

Junghans, S., Sangmeister, E., Schröder, M. (1968): Kupfer und Bronze in der frühen Metallzeit Europas. Studien zu den Anfängen der Metallurgie, vol. 2. Berlin.

Leisner, V. (1998): Die Megalithgraber der Iberischen Halbinsel. Der Westen. Berlin.

Lima, A. M. (2000): "Cinfães medieval", in L. M. S. Pinho e A. M. Lima (eds.), Antes de Cinfães. Da Pré-história à Idade Média. Monografia do Concelho de Cinfães, vol. II. Cinfães: 35-89.

López Sáez, J. A., Figueiral, I., Cruz, D. J. (2017): "Palaeoenvironement and vegetation dynamics in serra da Nave (Alto Paiva, Beira Alta, Portugal) during the Late Pleistocene and Holocene", in Actas da Mesa-Redonda «A Pré-história e a Protohistória no Centro de Portugal: avaliação e perspectivas de futuro» (Mangualde, Nov. 2011). Estudos Pré-históricos, XVII. Viseu: 11-23.

López Sáez, J. A., López García, P., Cruz, D. J., Canha, A. J. (2000): "Paleovegetação e impacto humano durante a Pré-história Recente na região do Alto Paiva: palinologia do povoado do Bronze Final de Canedotes (Vila Nova de Paiva, Viseu)". Estudos Pré-históricos, 8: 161-185.

López Sáez, J. A., Valinho, A., Loureiro, S. (2002-03): "Paleovegetação na transição Bronze Final/ Idade do Ferro no Alto Paiva: palinologia do Castro de Vila Cova-à-Coelheira (Vila Nova de Paiva, Viseu)". Estudos Pré-históricos, 10-11: 157-173.

Loureiro, S., Marques, J. N., Valinho, A. (2006): “O Alto Paiva: ocupação humana no $1^{\circ}$ milénio a. C.”. Conimbriga, XLV: 105-123.

MacWhite, E. (1951): Estudios sobre las relaciones atlánticas de la península hispánica en la Edad del Bronce. Madrid.

Medeiros, C. A. (2000): "Considerações sumárias sobre as características geográficas da serra do Montemuro", in A. Oliveira et al. (eds.), Actas do Colóquio "Montemuro - a última rota da transumância”. Arouca - Viseu: 111-129.

Melo, A., Araújo, M. F. (2000): "Machado de bronze de Santo Tirso". Santo Tirso Arqueológico, 2 (3): 53-63.

Mendes, S. L. (2009): O Castro de Vila Cova-àCoelheira: a ocupação proto-histórica. Estudos Préhistóricos, 14. Viseu.

Mendes, S. L. (2017): "O Castro de Vila Cova-àCoelheira", in Actas da Mesa-Redonda «A Pré-história e a Proto-história no Centro de Portugal: avaliação e perspectivas de futuro» (Mangualde, Novembro 2011). Estudos Pré-históricos, 17. Viseu: 91-99. 
Monteagudo, L. (1965): "Hachas prehistóricas de Europa occidental (notas de un viaje). Conimbriga, IV: 13-35.

Monteagudo, L. (1977): Die Beile auf der Iberischen Halbinsel. Prähistorische Bronzefunde, IX.6. München.

Montero-Ruiz, I., Rovira Llorens, S., Delibes de Castro, G., Fernández Manzano, J., FernándezPosse, M. D., Herrán, J. I., Martín, C., Maicas, R. (2003): "High leaded bronze in the Late Bronze Age metallurgy of the Iberian Peninsula", in Archaeometallurgy in Europe (24-26 september 2003) (vol. 2). Milano: 39-46.

Moreira, V. (1924): Monografia do Concelho de Tarouca (História e Arte). Viseu.

Oliveira, A., Monteiro, A., Sousa, A. S., Silva, F., Vala, H., Oliveira, J. (eds.) (2000): Actas do Colóquio "Montemuro - a última rota da transumância". Arouca - Viseu.

Pedro, I. (1995): O Povoamento Proto-histórico na Região de Viseu. Faculdade de Letras, Universidade do Porto [Dissertação de Mestrado em Arqueologia].

Pinho, L. M. S. (1996): Subsídios para o Inventário Arqueológico do Vale do Bestança. Cinfães.

Pinho, L. M. S. (1997): Património Arqueológico do Vale do Bestança. Cinfães.

Pinho, L. M. S. (2000): “Antes de Cinfães (parte I). Da Pré-história ao crepúsculo da romanização", in L. M. S. Pinho e A. M. Lima, Antes de Cinfães. Da Pré-história à Idade Média, Monografia do Concelho de Cinfães, vol. II. Cinfães: 5-31.

Ribeiro, O. (1948): "Notícia do pastoreio na serra do Montemuro", in Miscelânia de Estudos à Memória de Cláudio Basto (org. de H. Basto). Porto: 333-339.

Ribeiro, O. (1994): "Beira Alta. Introdução geográfica", in Guia de Portugal. vol. III. Beira. II. Beira Baixa e Beira Baixa, 2a ed. Lisboa: 741-745.

Ribeiro, O., Almeida, J. P., Patrício, A. (1943): "Nota preliminar sobre a morfologia do Maciço da Gralheira". Boletim da Sociedade Geológica de Portugal, III (1-2): 81-85.

Ruiz-Gálvez Priego, M. (1986): "Navegacion y comercio entre el Atlántico y el Mediterráneo a fines de la Edad del Bronce”. Trabajos de Prehistoria, 43: 942.

Santos, A. T. (2000): “A Pedra dos Pratos (Covelo de Paiva, Moledo, Castro Daire, Viseu). Breve estudo interpretativo". Estudos Pré-históricos, 8: 113-124.

Santos, A. T., Cruz, D. J. (2013): "Monumentos megalíticos com pinturas e gravuras da área ocidental da serra do Montemuro: os dólmenes do Lameiro dos Pastores e do Chão do Brinco (Cinfães, Viseu)". Conimbriga, 52: 5-36.
Savory, H. N. (1951): “A Idade do Bronze Atlântico no sudoeste da Europa”. Revista de Guimarães, 61: 323-377.

Schermerhorn, L. J. D. (1980): Carta Geológica de Portugal na Escala de 1/50.000. Notícia Explicativa da Folha 14-C (Castro Daire). Lisboa.

Senna-Martinez, J. C. (1995): "Povoado do Cabeço do Castro de S. Romão", in S. O. Jorge (ed.), A Idade do Bronze em Portugal: discursos de poder. Lisboa: 61-65.

Silva, A. C. F. (2007): A Cultura Castreja no Noroeste de Portugal, $2^{\mathrm{a}}$ ed. Paços de Ferreira [1. ${ }^{\mathrm{a}}$ ed.: 1986].

Silva, E. J. L. (1993): “Représentations humaines sur deux monuments mégalithiques de la région Nord du Portugal", in 115ème Congrès des Sociétés Savantes (Avignon, 1990). Paris: 21-27.

Silva, E. J. L. (1994): "Megalitismo do Norte de Portugal: o litoral minhoto", in Actas do Seminário "O Megalitismo no Centro de Portugal", Mangualde, Novembro de 1992. Estudos Pré-históricos, 2. Viseu: 157-169.

Silva, E. J. L., Cunha, A. M. L. (1988-94): "Inventário Arqueológico do Concelho de Cinfães: primeiros resultados", in $1{ }^{\circ}$ Congresso Internacional Sobre o Rio Douro (1986). Gaya - Revista do Gabinete de História e Arqueologia de Vila Nova de Gaia, 6. Vila Nova de Gaia: 325-340.

Silva, E. J. L., Medeiros, M. I. A., Correia, A. L. (1997): Carta Arqueológica do Concelho de Resende. $1^{a}$ fase. Resende.

Silva, E. J. L., Rocha, M. J. M., Loureiro, O. M. C., Monteiro, C. I. S. N. (1996): Carta Arqueológica do Concelho de Castelo de Paiva. Porto.

Silva, F. A. P. (2004): "Megalitismo e tradição megalítica no concelho de Arouca: três mil anos de arquitectura funerária", in A. M. S. P. Silva (coord.), Memórias da Terra. Património Arqueológico do Concelho de Arouca. Arouca: 44-203.

Silva, F. A. P., Silva, A. M. S. P. (1994): "Menires de Alvarenga e da serra da Freita/Arouca, Aveiro): breve notícia", in Actas das $5^{\text {a }} \mathrm{S}$ Jornadas Arqueológicas (vol. 2). Lisboa: 109-123.

Soares, A. M., Valério, P., Frade, J., Oliveira, M., Patoilo, D., Ribeiro, I., Arez, L., Santos, F., Araújo, M. F. (2007): “A Late Bronze Age stone mould for flat axes from Casarão da Mesquita 3 (São Manços, Évora, Portugal)", in Proceedings of the 2nd International Conference "Archaeometallurgy in Europe”. Milano: 145-157.

Suárez Otero, J. (2000): "Las hachas de talón sin anillas y la introducción del Bronce Atlántico en el NO Hispánico". Boletín Auriense, 30: 9-46.

Teixeira, C. (1939): "Molde de fundição para machados de bronze de duplo anel". Trabalhos da 
Sociedade Portuguesa de Antropologia e Etnologia, IX (1-2): 126-130.

Valério, P., Araújo, M. F., Senna-Martinez, J. C., Vaz, J. L. I. (2006): “Caracterização química de produções metalúrgicas do Castro da Senhora da Guia de Baiões (Bronze Final)". O Arqueólogo Português, série IV, 24: 289-319.

Valinho, A. J. (2003): A ocupação humana no Alto Paiva durante o I milénio a. C.: uma abordagem espacial. Faculdade de Letras, Universidade do Porto [Dissertação de Mestrado].

Vasconcelos, J. L. (1897-1913): Religiões da Lusitânia (vols. I-III). Lisboa.

Vasconcelos, J. L. (1904): “Acquisições do Museu Ethnologico Português”. O Arqueólogo Português, IX: 308-310.

Vasconcelos, J. L. (1913): "Aquisições do Museu Ethnologico Português”, O Arqueólogo Português, XVIII: 131-168.

Vasconcelos, J. L. (1927): De Terra em Terra. Excursões arqueológico-etnográficas através de Portugal (Norte, Centro e Sul) (vol. I). Lisboa.

Vasconcelos, J. L. (1933): Memorias de Mondim da Beira. Lisboa.
Vaz, J. L. I. (1995): “Arqueologia”, in A. Correia, A. Alves, J. L. I. Vaz (coords.), Castro Daire, $2^{\mathrm{a}}$ ed. Castro Daire: 85-129.

Vaz, J. L. I. (1997): A Civitas de Viseu (Espaço e Sociedade). 2 vols. Coimbra.

Vieira, M. A. (2004): Alto Paiva. Povoamento nas épocas romana e alto-medieval. Trabalhos de Arqueologia, 36. Lisboa.

Vieira, M. A. (2006): “Alguns aspectos do povoamento tardo antigo e alto medieval do curso superior do rio Paiva: as sepulturas escavadas na rocha". Conimbriga, 45: 311-335.

Vilaça, R. (2007): Depósitos de bronze do território português. Um debate em aberto. Conimbriga Anexos, vol. 5. Coimbra.

Vilaça, R., Bottaini, C., Montero-Ruiz, I. (2012): “O depósito do Cabeço de Maria Candal, Freixianda (Ourém, Portugal)". O Arqueólogo Português, série V, 2: 297-353.

Vilaça, R., Cruz, D. J. (1995): “Canedotes (Vila Nova de Paiva, Viseu). Povoado pré-histórico do Bronze Final". Estudos Pré-históricos, 3: 225-261. 